
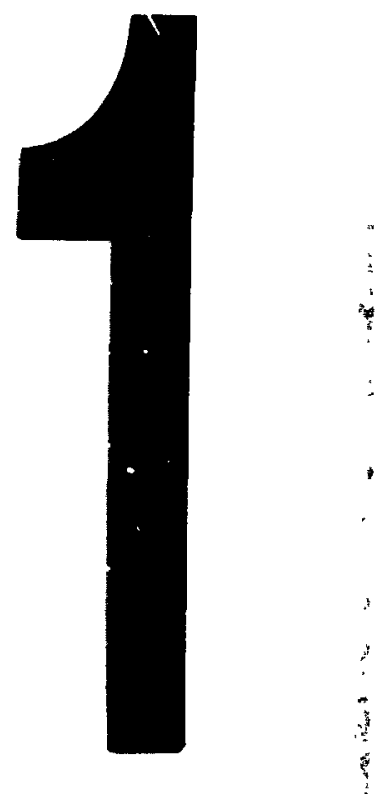

PN: ; 31/2"X4" PHOT JGRAPHIC MICROCOPY TARGET NBS IU10a N'4SI/ISO \#2 EQUIVALENT

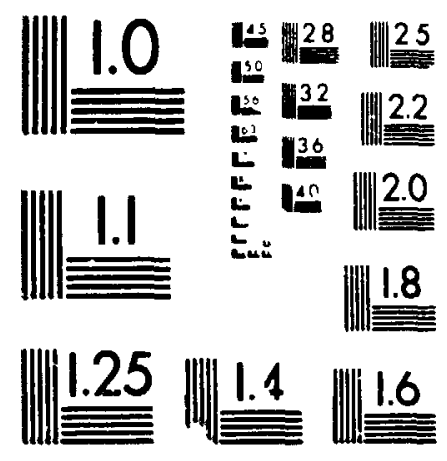




\section{National l ibrary
of Canada}

\section{Canadian Theses Service}

Otrawa, Canada

KIA ONA
Bibliotheque nationale du Canada

\section{Service des thèses canadiennes}

\section{NOTICE}

The qualuty of this microform is heavily dependent upon the quality of the original thesis submitted for microtilming. Every effort has been made to ensure the highest quality of reproduction possible.

If pages are missing, contact the university which granted the degree.

Some pages may have indistinct print especially if the original pages were typed with a poor typewriter ribbon or if the university sent us an interior photocopy.

Reproduction in full or in part of this microform is governed by the Canadian Copyright Act, R.S.C. 1970. C. C-30, and subsequent amendments.

\section{AVIS}

La qualité de cette microlorme dépend grí dement de la qualité de la these soumise au microlilmage Nous avons tout fait pour assurer une qualité supérieure de reproduc tion

S'il manque des pages, veuillez communiquer avec luniversité qui a conféré le grade

La qualité d'impression de cenaines pages peut laısser à désirer, surtout si les pages originales ont élé dactylogra. phiées à l'aide d'un nban usé ou si l'université nous a tait parvenir une photocopie de qualité inlérieure.

La reproduction, méme partielle, de celte microforme est soumise à la Loi canadienne sur le droit d'auteur, SRC 1970, c. C-30, et ses amendements subséquents. 


\title{
DIFFERENCES IN PERCEPTION OF COMMUNICATION ACROSS LEVELS OF PERCEIVED FAMILIAL DYSFUNCTION *
}

\author{
Lianne M. Walker
}

\begin{abstract}
A thesis submitted to
the Faculty of Graduate Studies and Research

in partial fulfilment of

the requirements for the degree of

Master of Arts
\end{abstract}

Department of Psychology

Carleton University

Ottawa, Ontario

September, 1991

copyright

1991, Lianne M. Walker

* This research was partially funded with a grant from the Faculty of Graduate studies 
which they have identified as having communication difficulty, able to recognize and suggest corrections for "bad" communication skills in others, or are they unaware of dysfunction in their communicatic.?" Although no research was found dealing with this specific issue, there is some research which suggests that certain interpersonal skills and social abjilty is transgenerational. Early theory tends to focus on the families of identified patients, mainly schizophrenics. Current research addresses issues such as drinking behaviour, self-esteem, abuse, and loneliness.

\section{The family as a factor in the Identified Patient}

Early research which began focusing on the family system as a factor in mental illness started in the 1950's with a group of psychiatrists. This group departed from the individual psychoanalytic approach, and began to treat patients in a family context (Gottman et al, 1979). As these clinicians (among others) began to treat their patients in a family or group context, it became accepted that the problems of the patient were related to the system they were in. The system was not meeting the needs of the individual and/or vice versa. Therapeutic goals were therefore set to help reorganize the family system and the individual's part in that system to better meet his or her needs. The 1950's saw the developme.zt of three major theories of how families "create" or "engender" 
The undersigned recommend to the Faculty of Graduate studies and Research acceptance of the thesis

\section{DIFFERENCES IN PERCEPTION OF COMMUNICATION ACROSS LEVELS OF PERCEIVED FAMILIAL DYSFUNCTION}

submitted by Lianne M. Walker

in partial fulfilment of the requirements for the degree of Master of Arts
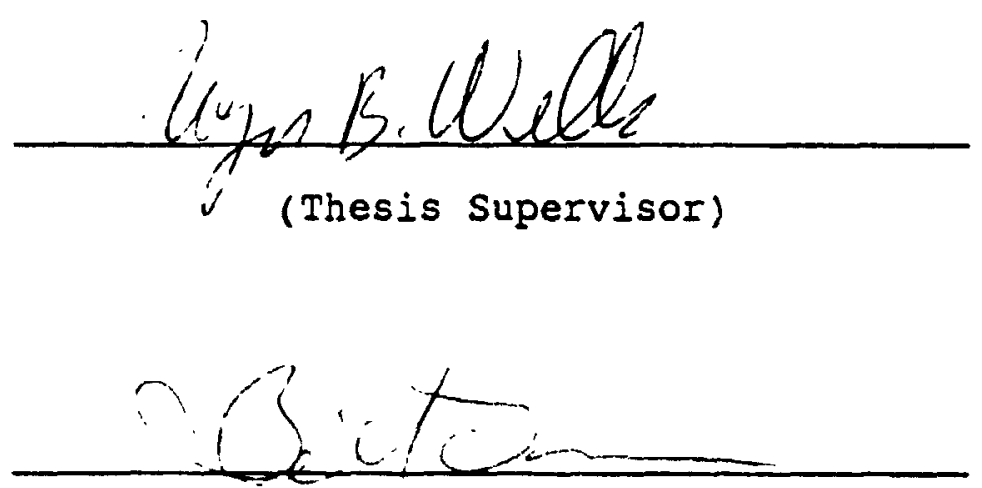

Chair, Department of Psychology

Carleton University

September, 1991 


\section{Abstract}

Communication is a commonly recurring theme in the literature dealing with dysfunction in families and in intimate relationships. While inter-generational links have been established for a variety of other variables associated with dysfunction (e.g. self esteem, loneliness, drinking behaviours, values and attitudes), similar links have not been clearly established for communication skills. One hundred fifty eight participants, premeasured on the McMaster Family Assessment Device were divided into three groups representing high, moderate and low levels of dysfunction. They were then randomly assigned ts watch a video of Good, Bad, or Ambiguous communication. Results suggest that the moderate group was not as accurate in judging the success of an interaction; focused more on outcome than interaction when judging success, and; gave more detail in their responses when communication was ambiguous. The high dysfunction group focused more on the negative aspects of ambiguous communication than did the low dysfunction group. Gender effects were also observed. Clinical implications and possible directions for future research are discussed. 
Table of Contents

Acceptance sheet Abstract

Table of Contents

List of Tables

List of igures

List of Appendices

Acknowledgments

Introduction

The Family as an Agent of Social Learning

The Family as a Factor in the Identified Patient

Communication

Communication and the Family

Communicationa and Intimate Relationstips

operationalizing Communication

Page

ii

iii

iv

$v$

vi

vii

viii

Materials

Premeasures-The McMaster Family Assessment Device 26

The Scripts

The Questionnaire

Pilot 1

Method

Results and Discussion

Pilot 2

Method

Results and Discussion

The Actual study

Results

Participants

46

Demographics

48

Manipulation Check

49

Analysis of Rating scales

53

Analysis of Open-ended Questions

Discussion

Overall Ratings of the Quality of Communication

Effects of Gender

65

Clinical Implications

References 


\section{LIST OF TABLES}

TABLE

1

2

3

4

5

6

7

8

9

10

11

12

13

14

15

DESCRIPTICN

PAGE

Characteristics of the communication of nondistressed versus distressed relationships.

Means, standard distrubutions and alphas for the Communication and General Functioning subscales of the FAD.

Sensitivity and specificity of various cutoff scores for the Communication and General Functioning subscales.

Means and standard deviations of the FAD for the present sample.

Mean scores of the FAD for the three levels of dysfunction.

Reliabilities of the scaled rating scores

Differences in global ratings of the quality of communication in the three videotapes.

Paired t-tests of participants ratings of the two characters.

ANOVA of participants' ratings of the three tapes.

ANOVA of overall ratings of the three videos by levels of dysfunction.

Mear ratings of the quality of communication by video and level of dysfunction.

Distribution of participants across the cells of the design.

Planned comparisons of mean ratings of overall quality of communication within each video by the Functional group.

Cell means of participants' ratings of the overall quality of communication in the video. 51

ANOVA and planned contrasts of overall ratings of the ambiguous video across levels of dysfunction. 
16 Repeated measure, within-subjects effect of participants' ratings of the two characters on the same variable.

17 Difference scores between participants. ratings of the two characters on the same variable.

Concordance rates of the two independent raters for the recall of events in the video.

19 Concordance rates of the two independent raters for the open-ended questions.

Univariate F-test of the main effect of gender 62

Group means and univariate F-tests for the main effect of dysfunction.

\section{LIST OF FIGURES}

Direction of the global ratings of the three tapes. 


\section{LIST OF APPENDICES}

IMDEX

PAGE
A
McMaster Family Assessment Device
B
Background information and Scripts
78
C
Pilot 1 Questionnaire
90
D
Final Questionnaire
95
$\mathbf{E}$
Scoring Criteria for Open-ended Questions 


\section{Acknowledgements}

This thesis is dedicated to Andrew Craxford, whose seemingly endless patience, love, understanding, and continuous support and friendship through the last months of this project undoubtedly enabled me to complete it with some samblance of sanity remaining.

As always one fears missing some of the many people who had some contribution to the completion of this thesis, therefore I preface my acknowledgements with a general thank-you to the many people who have helped me to accomplish this often frustrating and $s$. times, seemingly insurmountable challenge.

Many thanks and realms of appreciation go to Roger wells for lending a critical eye, a sense of humour, and a supportive shoulder when they were needed most.

As always and without reservation many thanks go to my parents, Pat and Bill who also did all of the above not only during this project, but for as long as I can remember.

Heaps of appreciation go out to Debbie and Malcolm Anderion, Lisa Carver, Jim Hill and Theresa and Luc St. Cyr. I never lacked for a sympathetic ear, a critical sounding board, a partner in crime, or even a stir-fry when I wes too exhausted to cook as long as they were around. And they were always around without fail.

Thanks also to Connie Kristiansen for all she taught me (whether I liked it or not) and to Kim Matheson as well for their continued support and friendship.

In producing the videotapes for this thesis, many people volunteered their time and effort to this end. Thank you to Al Phoenix, Morry Altman, Kitt, Scott and Tuck of the Stuntmakers, Bruce and the Crew at Carleton Media Services, and Dorothy and John Craxford for lending crucial equipment when it was needed. 
Introduction

Dysfunction in relationships, (e.g., family, marital, etc.) can be seen as a cluster of problems in a variety of skills or aspects of interpersonal functioning. Epstein, Baldwin, and Bishop (1983), isolate seven different subcategories of "dysfunction" in their McMaster Family Assissment Device. They are: problem solving, roles, affective responsiveness, affective involvement, behaviour control, general functioning, and communication. Similar sub-categories have been identified by other researchers in family assessment (Formant \& Hagan, 1984). While each of these categories can be seen as relatively independent, the sub-category of communication pervades or uverlaps a number of the other categories. For example, good communicatior. skills are likely necessary for effective problem solving, an adequate definition of roles, and the expression of emotions among individuals within a relationship. For this reason, communication will be examined specifically as it relates to dysfunction generaliy.

The etiology of "dysfunction" is an important issue at this point. If aspects of "dysfunction" are passed on to new generations of the family, how are the relationships of this new generation effected? Specifically, if "bad" communication skills are intergenerationally transmitted, then it might be hypothesized that the relationships of 


\section{Materials}

\section{Premeasures.}

The McMaster Family Assessment Device (FAD) was used to assess participants perceptions of familial dysfunction. The FAD is a 53-item questionnaire which asks individuals to rate each item with regard to their perceptions of their own family, on a four-point scale where one represents "strongly agree" (see Appendix A). Items are then grouped into seven subscales, and responses are averaged across the items. A higher score indicates higher levels of dysfunction. For the purposes of this study, only the communication and general functioning subscales will be used. While there is some limitation in that the FAD will only represent the students perceptions of their family, there is some evidence that children's perceptions of parents are more predictive than the parents perceptions of the same milieu (Gecas \& Schwalbe, 1986). Further, as will be illustrated, the FAD shows discriminant valicicy based on an individual FAD scores from clinical and nonclinical families (Miller et al, 1985).

The FAD was developed to identify problem areas in the most simple and efficient manner possible. It was chosen for the present study as it was a brief screening device suitable for inclusion in the Fall Mass Testing format; it provided information on a variety of dimensions of family 
of the child's self-concept (Hoffman et al,1988). The example which is set in the family environment may be critical to the development of the child and the young adult $s / h e$ is to become.

The popular 'systems approach' to understanding "dysfunctionality" shifts the focus from the individual to the family system. Virginia satir (1983) stipulates that there is an essential relationship between an individual and his/her family, and this set of relationships and rules represent a 'system' which may or may not operate to each member's satisfaction. This 'family system' is the forum within which the child will be provided with examples of problem-solving, communication, role responsibilities, emotional responses, and behavioural appropriateness. Certain rules will be established which dictate the "correct" response to specific situations, and the family system defines the rules. Therefore, "dysfunction" in families may produce "dysfunction" in adults. If this is the case, then the question is raised: "Are the adults who emerge from families which are perceived as having problematic systems, able to break free of this influence, cr are they subject to the limitations of the system?" This study will attempt to address this issue focusing on communication as the variable of interest. The question is raised: "Are young adults who have emerged from families 
which they have identified as having communication difficulty, able to recognize and suggest corrections for "bad" communication skills in others, or are they unaware of dysfunction in their communicatic." Although no research was found dealing with this specific issue, there is some research which suggests that certain interpersonal skills and social abjilty is transgenerational. Early theory tends to focus on the families of identified patients, mainly schizophrenics. Current research addresses issues such as drinking behaviour, self-esteem, abuse, and loneliness.

\section{The family as a factor in the Identified Patient}

Early research which began focusing on the family system as a factor in mental illness started in the 1950's with a group of psychiatrists. This group departed from the individual psychoanalytic approach, and began to treat patients in a family context (Gottman et al, 1979). As these clinicians (among others) began to treat their patients in a family or group context, it became accepted that the problems of the patient were related to the system they were in. The system was not meeting the needs of the individual and/or vice versa. Therapeutic goals were therefore set to help reorganize the family system and the individual's part in that system to better meet his or her needs. The 1950's saw the developme.zt of three major theories of how families "create" or "engender" 
schizophrenics. The "Double Bind Theory" (Bateson et al, 1956), proposed that the schizophrenic's family placed hin/her in a double bind. Put simply, this is a basic conflict set up on different levels of communication (verbal and non-verbal/ communication and metacommunication), as well as situational constrints which prevented the child from clarifying the conflict.

A second theory was proposed by Lidz, Conelson, Fleck, and Terry (1957), who observed two basic types of schizophrenogenic marriages among the parents of schizophrenic patients. The two types of marriages are the marital schism, and the marital skew. A marital schism is characterized by chronic hostility between the spouses where communication was largely distinguished by coercion and defiance and was usually impeded by mutual withdrawal, and the masking of motives. A marital skew involves a domineering, pathological figure whose pathology is supported by the other partner. This psychopathology is treated as normal by the spouse and the considerable masking of potentiel sources of conflict creates an unreal atmosphere. Thus, there exists a considerable rift between what is said and admitted and what is actually felt and done by the participants. Both of these marital types result in an open expression of fear by one spouse that the child will resemble the other spouse, and thus, this resemblance to one parent becomes a source of concern or rejection by the 
than solving their problems, these couples increase tension, frustration, and anxiety.

Since communication is a skill passed from one family generation to the next, it seems reasonable to conclude that young adults emerging from a family with maladaptive communication rules are at risk in their future intimate relationships if they have accepted the "rules" of the family. If they have incorporated these "rules" into their behaviour, then they would need to relearn or correct these "rules". In order to better begin to understand exactly what rules would need to be corrected, a closer examination of the various aspects of communication is indicated.

\section{Operationalizing communication}

In Satir's view there are two levels of comminication: the denotative level, or the literal content; and the metacommunicative level which acts as a comment on the literal comment (Satir, 1983). Tone, body language, and facial expression all combine to create the whole message as it is interpreted and thus understood. Thus, communication cannot simply be measured from the verbal or literal content. Nonverbal content flavours the literal so that the intent of the message is understood. Intent cannot be derived from the literal alone. Any definition of communication must therefore involve aspects of both the literal and the non-verbal. 
groups with regard to the theoretical concepts of systems theory. The lack of empirical evidence for group differences does not necessarily imply that there are no differences between the families in these groups or that family-oriented theories are not supported, but rather that the methodology has been weak (Olson,1980; Gottman et al, 1979). Specifically, the concepts of system theory were never intended to be cased in observation language. The present study will attempt to better quantify the relationship between dysfunction within families and dysfunctional problems among the adults emerging from these dysfunctional families with regard to their recognition of certain patterns of communication.

A second problem exists with regard to this identified patient perspective in that it forces corclusions to be drawn on a relatively limited population and, given the often extreme symptoms of the patients, they may not generalize to non-clinically troubled families. Further, given the interactive nature of the family system, it is difficult to delineate any causal relationship between the behaviour of the identified patient and the behaviour of his/her family. While therapeutically important in terms of treatment, the conclusions drawn from these studies cannot necessarily predict the future behaviour of adults who are not identified patients but who have emerged from a dysfunctional family. These young adults may still have 
developed inadequate social skills within this system which could result in difficulty with social relationships.

Although communication has not been addressed directly, research has attempted to shed light on the transmission of certain cnaracteristics from one generation to another in non-clinical populations. This research addresses the transgenerational transmission of a range of variables from specific behaviours (e.g., adolescent drinking), personality variables (e.g., self-esteem, interpersonal competence), to the family's values and attitudes. Evidence from these studies shows support for the transgenerational transmission of these variables from parents to children (Barnes, Farrel, \& Cairns, 1986; Filsinger \& Lamke, 1983; Gecas \& Schwalbe, 1986; Lobdell \& Perlman, 1986; Miller \& Glass, 1989). It might therefore be said that parents bequeath certain family-system characteristics to their children. The present study will explore whether or not "communication skills" are among these.

\section{Communication}

As was mentioned above, the common recurring theme in the literature dealing with dysfunction is that of communication. While dysfunction can be measured in terms of a variety of labels - e.g., affect, roles, behavioral appropriateness, problem solving (Epstein et al, 1983), communication can be seen as being part of all of these 
variables, for without communication, none of these issues could be taught effectively to the next generation. Further, if the individual's basic communication is problematic, then even if the skills were present, they might not be used effectively.

$$
\text { Virginia Satir }(1972) \text { has stated that: }
$$

Once a human being has arrived on this earth, communication is the largest single factor determining what kinds of relationships he makes with others, and what happens to him in the world about him. (p 30)

She also suggested that the communication which people use can be seen as a reliable indicator of interpersonal functioning. Based on this premise, communication will be explored as the variable to be operationalized to measure skills in social relations.

\section{Communication and the Family}

Communication connects the family system, defines the boundaries of the system and the relationships existing within it (Seiburg, 1985). Families can be viewed in terms of three generations which consist of: a) the parents as children learning implicit and explicit rules from their own parents; b) the parents as architects of their present family; and c) the future or actual married children who have learned or are learning how to become adults (Satir, 1983). The focus of the present study is this third 
generation. How have they learned to interact as adults?

According to Satir, implicit and explicit rules are woven into the family system by the first and second generations. This can be accomplished either:

a) directly.

b) by ignoring their existence and projecting the rules onto something else (which is external to the family).

c) by denying their existence and doing the opposite.

d) by distorting the rules in some way.

e) by comfortably discarding the rules altogether.

(Satir, 1983, p 146)

If the family's rules for communication are dysfunctional, methods a), b), and d) seem likely to perpetuate the dysfunction. If the rules are accepted directly, no changes are made, and dysfunction is perpetuated. If the rules are projected onto something external, then attempts to correct the problems will be focused on the wrong cause, or more detrimentally if the external agent is something like "society" family members may believe the rules cannot be changed. If the rules are distorted, one could end up with rules which are even more dysfunctional than the originals. Method c) may or may not perpetuate dysfunction, as the "opposite" is not always the best alternative (e.g., if the rule is to always agree and give in, the opposite would be to always be stubborn and never give in: neither alternative is highly productive in a relationship). Finally, method e) facilitates the chance of replacing the existing dysfunctional rules with functional ones. The 
question remains as to which trend is most common among young adults emerging from

dysfunctional families. Existing literature is insufficient in this area.

Communication and intimate relationships.

In terms of intimate relationships, communication is of vital importance. A number of researchers have established that communication is essential for the marriage to be successful in terms of sexuality, measures of general satisfaction, and in predicting future happiness (Markman, 1981; Masters \& Johnson, 1979; Murphy \& Mendelson, 1973; Navran, 1967). Markman found that in a five year longitudinal study, ratings of the quality of communication at the beginning of the marriage were the only variables to reliably predict happiness after five years.

Different patterns of interacting and communicating have been found between relationships with high levels of satisfaction and those with low levels.

Hooley and halweg (1989) found that high levels of marital satisfaction were associated with verbal acceptance of the partner and positive nonverbal behaviour. Alternatively, low levels of marital satisfaction were associated with negative nonverbal behaviour, criticism, and disagreement. Further, the distressed couples were more likely to reciprocate negative behaviour in terms of both 
verbal and nonverbal behaviour. These differences were especially marked with regard to negative affect. When a partner of a distressed marriage reacted negatively to a negative nonverbal stimulus from the other partner, the situation inevitably escalated with reciprocal negative behaviours. Navran's (1967) results support the hypothesis that couples who make a happy marital adjustment have commuication skills which allow them to deal effectively with the problems inherent in marriage. Conversely, those couples with poor marital adjustment had different communication styles resulting in poor problem solving, need frustration, and anxiety, tension and anger. Navran found that happily married couples:
a) talk more to each other;
b) convey the feeling that they understand what is being said to them;
c) have a wider range of subjects available to them;
d) preserve communication channels and keep them open;
e) show more sensitivity to each other's feelings;
f) personalize their language symbols; and
g) make more use of supplementary nonverbal techniques of communication.

(P 182)

Given the results reported above, it can be concluded that there are observable differences in communication skills of distressed versus nondistressed couples, the difference being that the partners in the distressed marriages have problems communicating. Conflicts escalate in negative affect and negative verbal and nonverbal signals, and rather 
than solving their problems, these couples increase tension, frustration, and anxiety.

since communication is a skill passed from one family generation to the next, it seems reasonable to conclude that young adults emerging from a family with maladaptive communication rules are at risk in their future intimate relationships if they have accepted the "rules" of the family. If they have incorporated these "rules" into their behaviour, then they would need to relearn or correct these "rules". In order to ketter begin to understand exactly what rules would need to be corrected, a closer examination of the various aspects of communication is indicated.

\section{Operationalizing communication}

In Satir's view there are two levels of comminication: the denotative level, or the literal content; and the metacommunicative level which acts as a comment on the literal comment (Satir, 1983). Tone, body language, and facial expression all combine to create the whole message as it is interpreted and thus understood. Thus, communication cannot simply be measured from the verbal or literal content. Nonverbal content flavours the literal so that the intent of the message is understood. Intent cannot be derived from the literal alone. Any definition of communication must therefore involve aspects of both the literal and the non-verbal. 
To study communication, "good" and "bad" or "functional" and "dysfunctional" communication must be defined. It has been shown that certain types of communication distinguish nondistressed marriages from distressed marriages (Gottman et al , 1979, 1976; Hooley \& Halweg, 1989; Navran, 1967; Satir, 1972, 1983). Examination of this literature revealed five main categories of difference in communication among distressed and nondistressed couples: 1) range, scope, and depth of communication; 2) acceptance of the validity of the spouse's position. 3) metacommunication; 4) nonverbal behaviour; and 5) affective tone.

The research cited above is summarized under these five categories in Table 1. 
Table One:Characteristics of the Communication of Nondistressed versus Distressed Relationships. Nondistressed

Distressed

\section{1) RANGE, SCOPE AND DEPTH OF COMgNicAtion}

Partners talk more to each other with a wider range of subjects available to them

(3)
Partners tend to shut out feedback, accuse, evade, rebuff, and restate without altering

Statements of the 'sender' are black and white. The receiver will agree or disagree. There is no moderation. (4)

Problem solving consists of offering counter-proposals. It is either win or lose.(2)

Partners coerce, vacillate, and postpone decisions. (4)

Communication is dishonest vague and indirect. (4)

\section{2) VALIDITY OF SPOUSE'S POSITION}

Criticism of partner, disagreement (1) partner (1)

Validate partner's position and feelings (2)

Complaint and validation(2)
Validation lacking (2)

Cross-complaining (2) 


\section{2) VALIDITY OF SPOUSE'S POSITION (cont'd)}

Convey the feeling that they understand what is being said (3)

Summarize the other person

\section{3) metacomanication}

They preserve common channels and keep them open (3)

will not agree or disagree with a statement that is ambiguous but will ask the sender to clarify or qualify (4)

They edit their own behaviour to control escalation

They make metacommunicative statements and easily move on from there. (2)

Mindreading is with neutral or positive affect (2)

\section{4) MONVERBAL BEHAVIOUR}

Partners use positive non-verbal behaviour

Make use of supplementary nonverbal techniques of communication (3)

Congruent messages are sent where the information at different levels do not seriously contradict each other. (4)
Greater negative impact of communication (2)

Summarize self (2)

Partners send incomplete messages (4)

They are unaware of their overgeneralization (4)

There is usually escalating reciprocity of negative behaviour during a conflict

Metacommunication is all absorbing and difficult to get beyond ( 2 )

Mindreading entails blaming and is critical and hostile

(2)

Partners use negative nonverbal behaviour (1)

Incongruent messages are sent where the information at different levels seriously contradicts each other (4) 
4) MONVERBAL BEHAVIOUR (cont'd)

If a message is incongruent they have the freedom to comment and query. (4)
If a message is incongruent there is no freedom to comment and query. (4)

Nonverbal behaviour of the listener is negative when the partner expresses feelings (2)

5) AFFECTIVE TONE

The atmosphere is congruent! There is 'blaming', or levelling. Each partner's position is validated and flexibility is apparent. (4)

Partners are more sensitive 'placating', 'super-reasonableness', or 'distraction. to each other's feelings(3)

Confrontations become a generalized attack on the partner as opposed to solving the immediate problem. (2)

There is more accusation, and more evaluation of the spouse's morals. (4)

KEY

(1) Hooley \&alweg, 1989

(2) Gottman et al, 1979

(3) Navran, 1967

(4) Satir, 1983

The above guidelines will be used as the basis for defining "Good" versus "Bad" communication in the present study. 


\section{Materials}

\section{Premeasures.}

The McMaster Family Assessment Device (FAD) was used to assess participants perceptions of familial dysfunction. The FAD is a 53-item questionnaire which asks individuals to rate each item with regard to their perceptions of their own family, on a four-point scale where one represents "strongly agree" (see Appendix A). Items are then grouped into seven subscales, and responses are averaged across the items. A higher score indicates higher levels of dysfunction. For the purposes of this study, only the communication and general functioning subscales will be used. While there is some limitation in that the FAD will only represent the students perceptions of their family, there is some evidence that children's perceptions of parents are more predictive than the parents perceptions of the same milieu (Gecas \& Schwalbe, 1986). Further, as will be illustrated, the FAD shows discriminant valicicy based on an individual FAD scores from clinical and nonclinical families (Miller et al, 1985).

The FAD was developed to identify problem areas in the most simple and efficient manner possible. It was chosen for the present study as it was a brief screening device suitable for inclusion in the Fall Mass Testing format; it provided information on a variety of dimensions of family 
functioning including communication; and finally, it was developed on a sample including families and Introductory psychology students (Epstein et ai, 1983), which suggests it was normed on a sample similar to the one used in this study.

The reported reliabilities of the FAD subscales range from .72 to .92 , and the six subscales are independent (when the seventh, General Functioning, was held constant) (Epstein et al, 1983). In terms of discriminant validity, individual FAD scores from 218 non-clinical and 98 clinical families were used to predict whether the family came from a clinical or non-clinical family. The discriminant analyses were statistically significant ( $\boldsymbol{Q}<.001)$, (Epstein et al, 1983), with the healthy families consistently scoring lower (more healthy) than the clinical families. Table 2 illustrates the means, standard deviations and Cronbach's alphas for the Communication and General Functioning scales to be used in this study.

Table 2. Means, Standard Deviations and alphas for the Communication and General Functioning subscales of the FAD.

Scale

Communication

General

Functioning
Mean

2.30

2.20

SD

Alpha

.51

.75

.58 .92 
Test-retest and concurrent validity were evidenced in the Miller et al (1985) study. Test-retest estimates ranged from .66 to .76 for the seven subscales (Communication= .72 , General Functioning $=.11)$. Concurrent validity was assessed by comparing the FAD to Faces II (Olsen, Sprenkle \& Russell, 1979) and the Family Unit Inventory (Vander Veen, Howard and Austria, 1970), and substantial relationships were observed providing good evidence for the concurrent validity of the FAD (Miller et al).

Miller et al (1985) also developed health/pathology cut off scores for the FAD. These were developed to maximize sensitivity and specificity. Alternative cutoff points were also suggested to maximize either sensitivity or specificity depending upon the particular research need. Table 3 presents the health/pathology cutoff scores as well as the alternative cutoff scores for the Communication and General Functioning Subscales.

Table 3. Sensitivity and specificity of various cutoff scores for the Communication and Seneral. Functioning subscales.

Scale

Communicaticn

2.3

2.2

2.1

2.2

2.0

1.8

eneral

Functioning

Diagnostic Sensitivity Specificity Confidence

.50

.67

.87
.67

.83

.90

.91

.73

.55

.73

.64

.45
.95

.89

.84

\begin{abstract}
1.8
\end{abstract}


There are some limitations to the FAD in termsof generalizability. It was normed on a population of white, middle-class, traditional-type families and therefore is not reliably generalizable to all people, for example, alternative families (gay couples) other races and ethnicities, the physically disabled, and it may have different implications for males and females. However, sirce the sample used in this study was largely a white, middle class, traditional type family, the instrument is appropriate for this group. However, anyu findings should be interpretted with this in mind.

For the present study, 1043 students registered in an introductory psychology course were administered the FAD along with a number of other (unrelated) questionnaires during Mass Testing in the Fall. The reliabilities for the Communication and General Functioning subscales from this sample were .53 and.88 respectively. It was noted that one item on the Communication subscale reduced the overall alpha for that scale. Therefore it was deleted and the resulting alpha was .63. Table 4 presents the means and standard deviation of the present sample. 
Table 4. Adjusted means and standard deviations of the FAD for the present sample $\mathrm{N}=1043$.

Scale

Communication

General Functioning
Mean

2.37

2.13
SD

1.28

.80

When these results are compared to the data from Epstein et al (1983), it can be seen that the means are similar; however, the standard deviations are greater. Because of this and the lower reliability of the ommunication subscale, it was decided that a higher cutoff score be used for the dysfunctional group to increase the specificity of the screening. Similarly a lower cutoff score for the functional group was used for the same reason. Thus, it was more likely that the Dysfunctional group in this sample was dysfunctional (high in both communication and general functioning) and the Functional group was functional (low in both of these areas).

For the present study, participants were divided into groups of low, moderate and high levels of dysfunction and these groups were labelled Functional, Moderate and Dysfunctional respectively. These categories were defined as follows: 
Low :

Those participants falling below the mean on the FAD Communication and General

Functioning subscales.

Moderate: Those participants who fall above the

clinical cutoff on the Communication

subscale but not on the General Functioning subscale.

High: Those participants falling above the clinical cutoff for both Communication and General Functioning.

Therefore the following cutoff scores were used:

Dysfunctional

Communication GT 2.30

General Functioning GT 2.30

\section{Moderate}

Communication

GT 2.30

General Functioning LT 2.00

Functional

Communication LT 2.00

General Functioning LT 2.00

The mean scores for the three groups in the present study are presented in Table 5. 
Table 5. Mean scores of the FAD subscales for the three levels of dysfunction.

Group

Dysfunctional

Moderate

Functional
Communication

2.41

2.47

1.79
General Functioning

2.59

1.61

1.57

Equal proportions of each group were shown each video.

The Scripts.

The scripts used to generate the three videos were developed to represent Good, Bad, and Ambiguous (a mixture of Good and Bad) communication in parallel scenarios. The scenarios involved the problem-solving of a young couple and varied with regard to the guidelines presented in Table 1. Each script was parallel in terms of events and consisted of 5 parts: 1) the introduction of the discussion; 2) addressing the problem 3) a distraction - the couple gets sidetracked from the main issue; 4) resolution; 5) denouement.

Identical background information was provided to the participants and wherever possible, dialogue and actions were kept identical. Most changes between videos involved tone of voice, reactions to suggestions, and nonverbal communication (see Appendix B for the three scripts). The points of variation among the scripts were based on the research summarized in Table 1. 
The Questionnaire.

Participants were given a questionnaire to complete after viewing the video (see Appendix D). It was developed specifically for this study. It consisted of a free recall section, where participants recounted the events of the video they viewed. Next, a series of open-ended questions asked participants about the communication to assess whether they recognized problems, whether they recognized solutions, and to look at self efficacy - would they implement the changes they suggested. Finally, the text of the script was handed out and participants were asked to rate the quality of both Ted's and Christine's communication on 22 specific questions also based on the findings summarized in Table 1. Nineteen of these 22 questions were then grouped into 5 subscales for each of the characters (three items were deleted as they lowered reliabilities, see Appendix D):

Mutual Acceptance between Partners (MA)

Cooperation with Partner (COOP)

Open to Partners' needs/feelings (OPEN)

Focused on Issue at Hand (FOCUS)

Nonverbal Communication (NONV)

In addition, all of the items were averaged into a general overall "quality of communication" score. The reliabilities of these scales are presented in Table 6 . 
Table 6. Reliabilities of s'aled rating scores

\begin{tabular}{|c|c|c|c|c|}
\hline Scale & Items & Mean & SD & Alpha \\
\hline $\begin{array}{ll}\text { Ted } & \\
& \text { MA } \\
\text { COOP } & \\
\text { OPEN } \\
\text { FOCUS } \\
\text { NONV }\end{array}$ & $\begin{array}{l}5 \\
5 \\
5 \\
2 \\
2\end{array}$ & $\begin{array}{l}3.55 \\
3.81 \\
4.36 \\
3.12 \\
3.82\end{array}$ & $\begin{array}{l}1.96 \\
2.13 \\
2.00 \\
2.16 \\
2.15\end{array}$ & $\begin{array}{l}.85 \\
.77 \\
.80 \\
.63 \\
.79\end{array}$ \\
\hline OVERALI & 19 & 3.86 & 1.79 & .93 \\
\hline $\begin{array}{c}\text { Christine } \\
\text { MA } \\
\text { COOP } \\
\text { OPEN } \\
\text { FOCUS } \\
\text { NONV }\end{array}$ & $\begin{array}{l}5 \\
5 \\
5 \\
2 \\
2\end{array}$ & $\begin{array}{l}4.09 \\
4.50 \\
4.81 \\
4.87 \\
4.36\end{array}$ & $\begin{array}{l}1.95 \\
2.00 \\
1.86 \\
2.24 \\
2.09\end{array}$ & $\begin{array}{l}.85 \\
.76 \\
.76 \\
.55 \\
.73\end{array}$ \\
\hline OVERALL & 19 & 4.55 & 1.73 & .93 \\
\hline
\end{tabular}




\section{P1lot 1}

Method

The first pilot was designed to test the scripts for the Good, Bad and Ambiguous conditions. The three scripts were read by the same actors onto audiotapes. Eight male and nine female participants $(\underline{M}$ age $=20.18)$ who had pretested as "Functional" on the FAD were randomly assigned to listen to one of the three tapes. "Functional" participants were chosen at this stage as they were to be the baseline against which the other two groups would be compared. Participants were asked to listen to these tapes carefully, as they would be filling out a questionnaire afterward. participants in each condition were given identical background information, on the characters on the tape and then the tape was played for them. After listening to the tapes, participants were asked to complete a questionnaire consisting of some rating scales and some open ended questions (see Appendix C). Finally, an open discussion ensued to obtain general feedback from the participants.

Results and discussion.

Participants rated the overall quality of the couple's communication on the tapes using a 9 -point scale where 1 was labelled 'Good', 5 was labelled 'Neither Good nor Bad' and 9 was labelled 'Bad'. A oneway analysis of variance (ANOVA) 
illustrated that participants did perceive the three tapes differently $(\underline{E}(2,14)=24.23, \underline{P}<.001)$. Further, a paired comparison of these means showed that differences on the ratings between each tape were statistically significant (with a corrected per comparison error rate of .016. See Table 7), and were also in the expected direction (see Figure 1).

Table 7. Differences in global ratings of the quality of communication in the three videotapes.

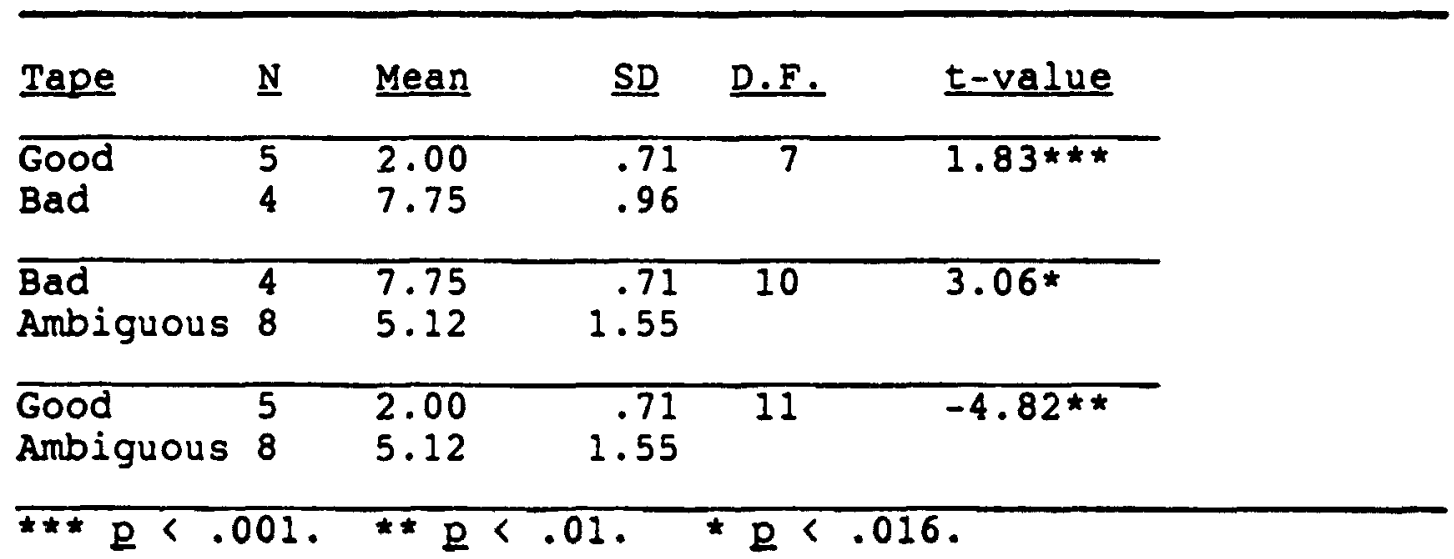


Figure 1. Direction of the global ratings of the three tapes.

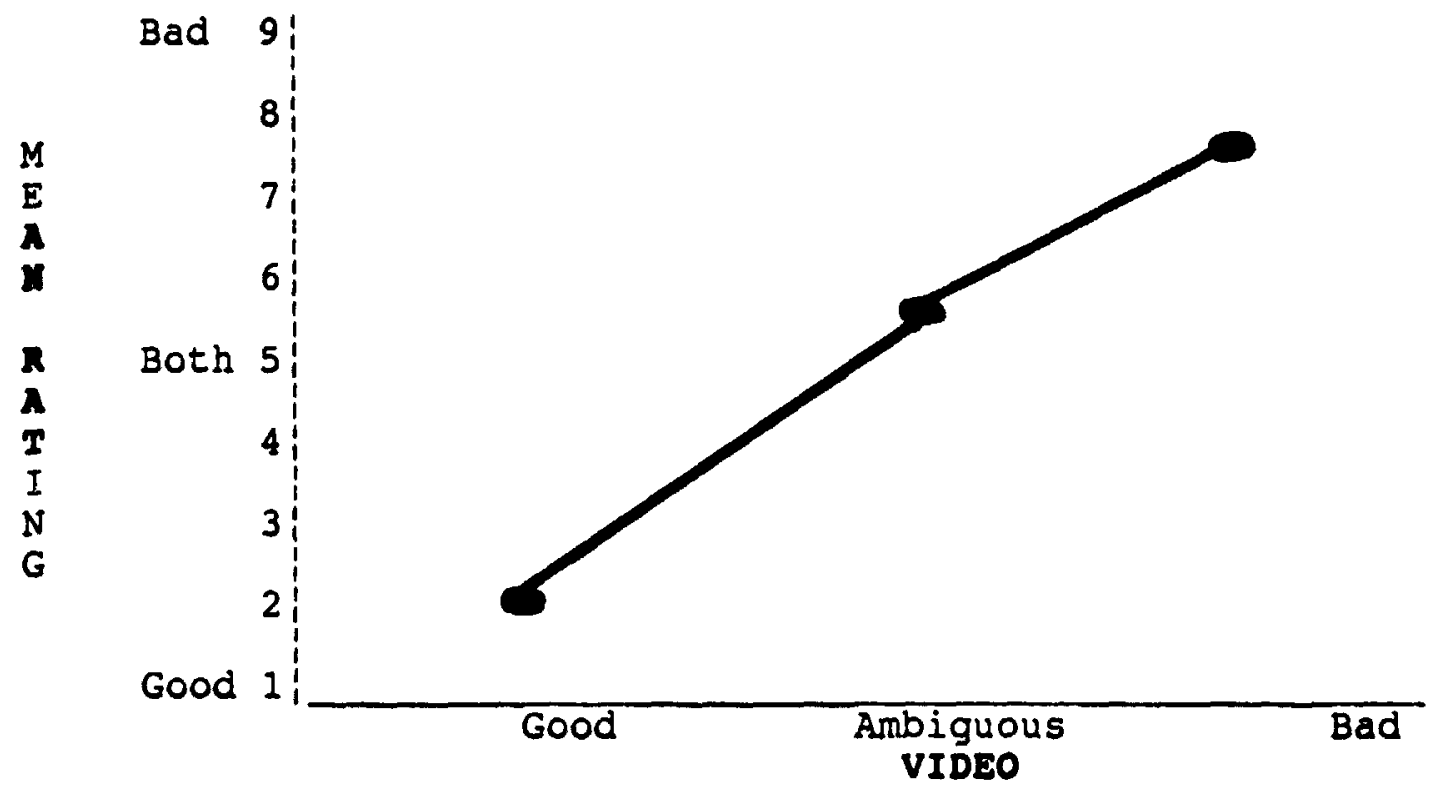

Thus, the Good tape was rated as "Good" , the Bad tape was rated as "Bad" and the Ambiguous tape was rated as "Neither Good nor Bad", and was rated differently from the other two tapes.

In addition to this global rating, ratings on a variety of variables tapping different factors of communication were obtained for both characters on the tape. A 9-point rating scale was used where 1 represents a negative rating, and 9 represents a positive rating. Paired t-tests revealed that with the exception of 4 variables, there were no significant differences between the ratings for the two characters (see Table 8). 
Table 8. Paized t-tests of participants ratings of the two characters $(n=17)$.

\begin{tabular}{|c|c|c|c|c|}
\hline Variable & Character & Mean & $\underline{\text { SD }}$ & $I(16)$ \\
\hline Pleased & $\begin{array}{l}\text { Ted } \\
\text { Christine }\end{array}$ & $\begin{array}{l}2.82 \\
5.76\end{array}$ & $\begin{array}{l}2.35 \\
2.56\end{array}$ & 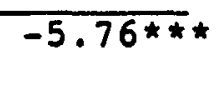 \\
\hline Accepting & $\begin{array}{l}\text { Ted } \\
\text { Christine }\end{array}$ & $\begin{array}{l}6.29 \\
6.29\end{array}$ & $\begin{array}{l}2.54 \\
3.02\end{array}$ & .00 \\
\hline $\begin{array}{l}\text { Under- } \\
\text { standing }\end{array}$ & $\begin{array}{l}\text { Ted } \\
\text { Christine }\end{array}$ & $\begin{array}{l}5.76 \\
5.88\end{array}$ & $\begin{array}{l}2.75 \\
2.83\end{array}$ & -.17 \\
\hline $\begin{array}{l}\text { Not } \\
\text { Critical }\end{array}$ & $\begin{array}{l}\text { Ted } \\
\text { Christine }\end{array}$ & $\begin{array}{l}2.82 \\
5.47\end{array}$ & $\begin{array}{l}1.91 \\
2.90\end{array}$ & $-3.72 \star \star$ \\
\hline $\begin{array}{l}\text { React } \\
\text { Positively }\end{array}$ & $\begin{array}{l}\text { Ted } \\
\text { Christine }\end{array}$ & $\begin{array}{l}3.70 \\
4.35\end{array}$ & $\begin{array}{l}2.57 \\
2.67\end{array}$ & -1.61 \\
\hline Compromise & $\begin{array}{l}\text { Ted } \\
\text { Christine }\end{array}$ & $\begin{array}{l}4.82 \\
4.64\end{array}$ & $\begin{array}{l}2.68 \\
2.62\end{array}$ & .19 \\
\hline Clear & $\begin{array}{l}\text { Ted } \\
\text { Christine }\end{array}$ & $\begin{array}{l}5.06 \\
5.53\end{array}$ & $\begin{array}{l}2.22 \\
2.55\end{array}$ & -.94 \\
\hline Open & $\begin{array}{l}\text { Ted } \\
\text { Christine }\end{array}$ & $\begin{array}{l}4.76 \\
5.94\end{array}$ & $\begin{array}{l}2.39 \\
2.70\end{array}$ & $-2.58 \star$ \\
\hline $\begin{array}{l}\text { Did not } \\
\text { Accuse }\end{array}$ & $\begin{array}{l}\text { Ted } \\
\text { Christine }\end{array}$ & $\begin{array}{l}4.35 \\
5.29\end{array}$ & $\begin{array}{l}2.76 \\
2.47\end{array}$ & -1.54 \\
\hline $\begin{array}{l}\text { Did not } \\
\text { Blame }\end{array}$ & $\begin{array}{l}\text { Ted } \\
\text { Christine }\end{array}$ & $\begin{array}{l}4.47 \\
4.88\end{array}$ & $\begin{array}{l}2.15 \\
2.73\end{array}$ & -.59 \\
\hline $\begin{array}{l}\text { Super- } \\
\text { reasonable }\end{array}$ & $\begin{array}{l}\text { Ted } \\
\text { Christine }\end{array}$ & $\begin{array}{l}6.64 \\
6.12\end{array}$ & $\begin{array}{l}1.58 \\
2.76\end{array}$ & .80 \\
\hline $\begin{array}{l}\text { Focused } \\
\text { on Issue }\end{array}$ & $\begin{array}{l}\text { Ted } \\
\text { Christine }\end{array}$ & $\begin{array}{l}2.82 \\
5.76\end{array}$ & $\begin{array}{l}2.16 \\
2.64\end{array}$ & $-3.75 \star \star$ \\
\hline Sensitive & $\begin{array}{l}\text { Ted } \\
\text { Christine }\end{array}$ & $\begin{array}{l}5.47 \\
6.41\end{array}$ & $\begin{array}{l}2.58 \\
2.48\end{array}$ & -1.25 \\
\hline
\end{tabular}

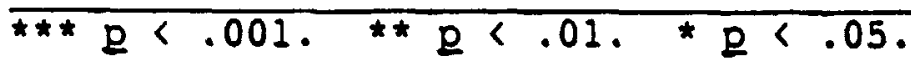

Where no differences were observed, the two ratings 
were averaged and a oneway ANOVA was performed to examine differences on these ratings between the tapes. Where differences were observed, oneway ANOVAs were performed on both ratings separately. Table 9 summarizes the findings. Generally speaking, most variables did differentiate between the tapes. Where no differences were found, an attempt was made to adjust the scripting and the acting to more clearly differentiate these factors.

Table s. ANOVA of participants ratings of the three tapes.

\begin{tabular}{|c|c|c|c|c|c|c|}
\hline \multicolumn{2}{|l|}{ Variable } & Good & Amb. & Bad & $F(2,14)$ & p-value \\
\hline \multicolumn{2}{|c|}{$\begin{array}{l}\text { Averaged Ratings } \\
\text { Acceptance } \\
\text { Understanding } \\
\text { Reaction Tone } \\
\text { Compromise } \\
\text { Clarity } \\
\text { No Accusation } \\
\text { Did not Blame } \\
\text { Not Super-reasonable } \\
\text { Sensitivity }\end{array}$} & $\begin{array}{l}8.3 \\
7.8 \\
6.8 \\
4.3 \\
5.6 \\
6.9 \\
6.0 \\
6.1 \\
7.4\end{array}$ & $\begin{array}{l}2.9 \\
3.2 \\
1.5 \\
5.4 \\
5.9 \\
2.6 \\
2.8 \\
7.1 \\
4.2\end{array}$ & $\begin{array}{l}6.8 \\
5.9 \\
3.6 \\
4.7 \\
4.8 \\
4.6 \\
4.8 \\
6.2 \\
5.9\end{array}$ & $\begin{array}{r}18.83 \\
7.02 \\
13.93 \\
.34 \\
.36 \\
6.67 \\
4.19 \\
.42 \\
3.75\end{array}$ & $\begin{array}{l}.000 \\
.008 \\
.000 \\
.715 \\
.702 \\
.009 \\
.038 \\
.662 \\
.050\end{array}$ \\
\hline \multicolumn{7}{|c|}{ Individual Ratings } \\
\hline Pleased & $\begin{array}{l}\text { TED } \\
\text { CHRISTINE }\end{array}$ & $\begin{array}{l}1.4 \\
3.4\end{array}$ & $\begin{array}{l}6.0 \\
8.2\end{array}$ & $\begin{array}{l}2.1 \\
6.0\end{array}$ & $\begin{array}{r}11.17 \\
7.16\end{array}$ & $\begin{array}{l}.001 \\
.007\end{array}$ \\
\hline Not Critical & $\begin{array}{l}\text { TED } \\
\text { CHRISTINE }\end{array}$ & $\begin{array}{l}4.0 \\
8.0\end{array}$ & $\begin{array}{l}1.8 \\
3.5\end{array}$ & $\begin{array}{l}2.6 \\
4.9\end{array}$ & $\begin{array}{l}1.78 \\
4.01\end{array}$ & $\begin{array}{l}.205 \\
.042\end{array}$ \\
\hline $\begin{array}{l}\text { Open to } \\
\text { Spouse }\end{array}$ & $\begin{array}{l}\text { TED } \\
\text { CHRISTINE }\end{array}$ & $\begin{array}{l}6.0 \\
8.2\end{array}$ & $\begin{array}{l}2.2 \\
1.8\end{array}$ & $\begin{array}{l}5.2 \\
6.6\end{array}$ & $\begin{array}{r}4.33 \\
39.98\end{array}$ & $\begin{array}{l}.034 \\
.000\end{array}$ \\
\hline $\begin{array}{l}\text { Focused } \\
\text { on Issue }\end{array}$ & $\begin{array}{l}\text { TED } \\
\text { CHRISTINE }\end{array}$ & $\begin{array}{l}4.0 \\
6.8\end{array}$ & $\begin{array}{l}1.8 \\
4.8\end{array}$ & $\begin{array}{l}2.6 \\
5.6\end{array}$ & $\begin{array}{r}1.32 \\
.66\end{array}$ & $\begin{array}{l}.297 \\
.530\end{array}$ \\
\hline
\end{tabular}




\section{Pilot 2}

Method.

From the information gathered during the first pilot of the scripts, three videotapes were developed. Since the scripts involved characters who were described as being 23 years of age, potential actors were piloted to ensure they would be perceived as being in this age range. To accomplist. this, a series of headshots were obtained and students in a second year psychology class $(N=73)$ were asked to guess the age of the individuals in the six head shots. The students' Iesponses were averaged and actors were chosen based on the mean age that students' perceived them to be. The male and female actors chosen to perform in the video had averaged ratings of 23 years of age.

The videotapes included the same basic scripts used for the audio tapes with certain changes in emphasis and direction. This was to enhance differences between the tapes with regard to the variables that did not differentiate the tapes in the first pilot. The same actors and set were used for all three videos. Once the three videos were developed eight male and nine female participants who had been premeasured on the FAD as "Functional" or "Dysfunctional" were randomly assigned to view one of $t^{\prime}$ : tillee videotapes. They were shown identical backgr ad information in all three conditions and asked to watch the video closely. After viewing the video, they 
completed a questionnaire consisting of open- ended questions and questions answered by circling a number on a 9-point rating scale. The "moderates" were not included at this stage as there was a limited number of potential subjects and it was not deemed prudent to use any of this sample during piloting.

Results and discussion.

Initially only those participents classified as "Functional" were included in the analyses to verify that this comparison group still rated the three videos differently, A oneway ANOVA revealed a similar trend to that observed in the audiotape pilot. Participants did differentiate between videos $(E(2,8)=13.57, \underline{p}(.01)$, and, as with the first pilot, the direction was as expected. Subsequently a $2 \times 3$ (type of video by level of dysfunction) ANOVA was performed to investigate whether differences could be observed across the levels of dysfunction as well. As is presented in Table 10, an interaction of video type and level of dysfunction was observed $(\underline{F}(2,16)=5.89$, $\mathrm{Q}<$ .05 ). Examination of the means (see Table 11) revealed that both the Functional group and Dysfunctional group rated the Good and Bad communication videos as relatively good and bad respectively. The "Ambiguous" video however, was rated differently by the two groups. The Functional group rated this video as having betcer communication than did the 
Dysfunctional group. (M (Functional)=6.4,

M (Dysfunctional $)=2.0$ on a scale of 1 to 9 , where 9 represents "good").

Table 10. ANOVA of overall ratings of the three videos by levels of dysfunction.

\begin{tabular}{|c|c|c|c|c|}
\hline Source & S.S. & D.F. & M.S. & F-value \\
\hline $\begin{array}{l}\text { Main } \\
\text { Video } \\
\text { Dysfunction }\end{array}$ & $\begin{array}{l}86.49 \\
71.16 \\
18.23\end{array}$ & $\begin{array}{l}3 \\
2 \\
1\end{array}$ & $\begin{array}{l}28.82 \\
35.58 \\
18.23\end{array}$ & $\begin{array}{l}18.62 \star \star \star \\
22.98 \star \star \star \\
11.78 \star \star\end{array}$ \\
\hline $\begin{array}{l}\text { Interaction } \\
\text { Video X Dysfunction }\end{array}$ & 18.24 & 2 & 9.12 & $5.89 *$ \\
\hline Explained & 104.73 & 5 & 20.95 & $13.53 * * *$ \\
\hline Residual & 17.03 & 11 & 1.55 & \\
\hline Total & 121.76 & 16 & 7.61 & \\
\hline
\end{tabular}

Table 11. Mean ratings of the quality of communication by video and level of dysfunction.

\begin{tabular}{lcc}
\hline Group & Functional & $\frac{\text { Dysfunctional }}{\text { Good }}$ \\
\cline { 2 - 2 } Ambiguous & 7.00 & 6.50 \\
Bad & 6.40 & 2.00 \\
& 1.33 & 1.33 \\
\hline
\end{tabular}

This suggests that when communication stimuli are clear, those from fuactional and dysfunctional families rate them 
similarly. When stimuli are ambiguous, however, then those from functional families rate them as 'good' while those from dysfunctional families rate them as 'bad'. Given that the pilot data suggested that differences may appear within the ambiguous video in particular, analyzing group means within this level of variable alone became a planned comparison in the actual study. Since a treatment effect was observed for both video and level of dysfunction, the questionnaire went under a final revision (fine-tuning) and the full study was undertaken. 


\section{The Actual Study}

Method.

One hundred fifty eight participants premeasured on the FAD and preselected on the basis of the scores of the Communication and General Functioning subscales. were randomly assigned to view one of the three videos developed for the second pilot study. As with the pilot studies, particifants in all three conditions were given identical background information on the characters in the video (see Appendix B). They were then told that the study they were participating in concerned itself with how people perceived communication. There was no mention of familial dysfunction at any point in the study as there was some concern over the possible impact this would have on the participants. Given that there was no opportunity for clinical counselling and follow-up, and that the FAD simply indicates probable dysfunction, but does not in itself, consist of a clinical diagnosis, it was decided that this aspect of the study not be discussed with participants. This avoided any possible misunderstanding of the FAD results, thus preventing the possible negative ramifications this may have had on participants and their families.

Participants were then randomly assigned to one of the three video conditions and were asked to watch the video tape carefully, paying atiention to what was said and how 
the couple interacted as they would be subsequently asked to fill out a questionnaire. Participants then viewed one of the three videos, after which they completed a questionnaire which consisted of open-ended questions (including freerecall of the video), and then a series of questions which asked them to rate the couple's communication on various factors of communication. The first section of the questionnaire was done from recall. For the second section, participants were provided a script of the dialogue for their particular video (see Appendix $D$ for questionnaire and Appendix $B$ for the scripts). Participants were then debriefed and any questions from the participants were answered at that time. 


\section{Results}

\section{Participants}

Eighty-three males and seventy-five females $(\underline{M}$ age $=$ 20.20 years) participated in this study. Table 12 shows their distribution in the cells of the design. It should be noted that there were unequal $n$ 's in the cells and therefore the tests of main effects and interactions are not necessarily independent.

Table 12. Distribution of participants across the celis of the design.

\begin{tabular}{ccccc}
\hline & Good & $\begin{array}{c}\text { Video } \\
\text { Ambiguous }\end{array}$ & Bad & TOTAL \\
$\begin{array}{c}\text { Level of } \\
\text { Dysfunction }\end{array}$ & & & & \\
$\begin{array}{c}\text { Functional } \\
\text { Males }\end{array}$ & 9 & 12 & 10 & 31 \\
Females & 8 & 8 & 9 & 25 \\
$\begin{array}{c}\text { Moderate } \\
\text { Males }\end{array}$ & 9 & & 8 & 25 \\
Females & 8 & 8 & 4 & 20 \\
$\begin{array}{c}\text { Dysfunctional } \\
\text { Males }\end{array}$ & 8 & 8 & 9 & 27 \\
Females & 9 & 10 & 9 & 30 \\
Total & 51 & 12 & 49 & 158 \\
\hline
\end{tabular}

The sample's mode for 'number of parents' was 2 (143 of the 158 participants), also 13 participants had 1 stepparent and 4 had 2 step-parents. Birth order was distributed across the various levels. Ten were only 
children, 57 were the youngest, 37 were middle children, and 54 were the eldest. Approximately half of the sample was still living with their family $(48.18)$. The remainder had been on their own an average of 10 months. Participants were asked about their current relationships, both romantic and close friendships. In this sample 62.68 were currently involved in a romantic relationship, which had lasted an average of 20.32 months. Of these relationships 31.38 were currently long distance. On a scale ranging from 0 to 8 , these participants were asked to rate how stable their current relationship was: the average rating was 5.83 . Considering close friends, 90.518 of the sample reported having at least one current close friend, with the average number being 3 . Of those participants not presently in a romantic relationship, 85.08 were actively pursuing one which was moderately intense ( 5.12 on a scale from 0 to 8 ). In terms of past relationships, 35.448 of the sample had never had a previous romantic relationship, and 36.718 had only one. The remainder sar batween 2 and 7 past romantic relationships. With regard to past close friendships, 82.38 of the sample reported having had close friendships in the past, the average being approximately 3 .

In summary, the participants in this sample are relatively young and they are either still at home or having recently left home. For the most part they come from "intact" families and represent a variety of birth orders. 
It should be explained that the percentage of participants residing in "intact" families may in fact be inflated. Upon examination of the questionnaire, it was noted that while participants were asked about the number of parents they had, the written instructions did not explain that divorced parents should be differentiated from married parents. Thus, it is very likely that a number of participants reported having two parents in their family of origin despite the fact that they live(d) with only one parent.

In terms of romantic relationships, this sample is relatively inexperienced in terms of total number of relationships, but more often than not are currently involved in one. They have also experienced close friendships both current and past.

\section{Demographics}

Each of the variables used to describe the sample were examined for possible confounds within the treatment effects. A $3 \times 3 \times 2$ ANOVA (video by dysfunction by gender) examined possible interactions and main effects associated with these denographic variables. An additional variable tested at this time was that of exposure to counselling environments (e.g. ALANON, ACOC, Family Therapy, Psychotherapy, etc. - see the questionnaire in Appendix C for a complete list). There was only one significant video by Dysfunction by Gender interaction which was observed 
within the "time apart from spouse" variable $(\underline{F}(2,32)=$ $5.26, \mathrm{Q}(.05)$. However, this only involved 35 of 158 cases, and therefore was noted but not pursued.

The variable "exposure to counselling environments" was found to be unequally distributed across the levels of video $(E(2,130)=3.20, \underline{D}<.05)$. Examination of the means revealed that there was greater exposure to counselling environments in the "Good" Video, than in the other two. This represents a potential confound in this study.

\section{Manipulation Check.}

To ensure that the three videos were still rated differently by the Functional group of participants, a oneway ANOVA was performed on the overall rating of quality of video which showed a significant effect due to video ( $\underline{E}$ $(2,53)=29.42, \underline{p}<.001)$. Planned contrasts of the three means revealed differences between each of the means (see Table 13 for summary). 
Table 13. Planned comparisons of mean ratings of overall guality of communication in each video by the Functional group.

\begin{tabular}{|c|c|c|c|c|}
\hline Contrast & Mean & $\underline{D F}$ & $t-v a l u$ & \\
\hline $\begin{array}{l}\text { Good vs. } \\
\text { Ambiguous }\end{array}$ & $\begin{array}{l}6.35 \\
5.15\end{array}$ & 53 & 1.84 & \\
\hline $\begin{array}{l}\text { Good vs. } \\
\text { Bad }\end{array}$ & $\begin{array}{l}6.35 \\
1.53\end{array}$ & 53 & 7.28 & $\star \star \star$ \\
\hline $\begin{array}{l}\text { Ambiguous } \\
\text { vs. Bad }\end{array}$ & $\begin{array}{l}5.56 \\
1.53\end{array}$ & 53 & 5.69 & $\star \star \star \star$ \\
\hline
\end{tabular}

A possible interaction of video by dysfunction by gender was then explored. A $3 \times 3 \times 2$ ANOVA on the rating of overall quality of communication in the video revealed that the three video tapes were rated differently by all three levels of dysfunction. A main effect due to the type of video on participants ratings of the overall quality of communication in the video was observed $(\underline{E}(2,140)=73.90$, $\underline{p}(.001)$. There was no main effect observed for level of dysfunction $(\underline{F}(2,146)=2.20$, n.s.) suggesting that participants perceived the same video similarly regardless of their level of dysfunction or their gender. Table 14 summarizes the sample means. 
Table 14. Cell means of participants ratings of the overall quality of communication in the video.

\begin{tabular}{cccc}
\hline Group & Good & Ambiquous & Bad \\
$\begin{array}{c}\text { Functional } \\
\text { Male }\end{array}$ & 6.25 & & \\
$\begin{array}{c}\text { Female } \\
\text { Moderate }\end{array}$ & 6.44 & 5.25 & 1.22 \\
Male & 5.88 & 5.08 & 1.80 \\
$\begin{array}{c}\text { Female } \\
\text { Dysfunctional }\end{array}$ & 5.44 & 4.50 & 2.75 \\
Male & 6.44 & 5.88 & 1.25 \\
Female & 5.75 & 3.42 & 0.78 \\
& & 4.50 & 1.78 \\
\hline
\end{tabular}

Since the findings of the second pilot suggested that the functionals and dysfunctional would perceive the Ambiguous video differently, the planned comparison of a oneway ANOVA with one planned contrast was performed. The overall $F$ ratio was not significant although marginal effects were observed for the contrast of Functional versus Dysfunctional groups (see Table 15). Thus the hypothesis that the Functional and Dysfunctional groups rated (perceived) the Ambiguous video differently had marginal support. The Dysfunctional group rated the video less positively than did the Functional group suggesting a difference in perception of identical stimuli. 
Table 15. ANOVA and planned contrasts of overall rating of the amblguous video across levels of dysfunction.

NyOVA

Source

DF SS MS $\quad$-value

Dysfunction

221.61

10.80

2.10, ns

Residual

$55 \quad 282.81$

5.14

Total

57304.41

PLARTED CONTRAST

Contrast

Functional vs.

Dysfunctional
DF Mean t-value

55

5.15

$1.77+$

3.91

$+\mathrm{p}<.10$. 


\section{Analyses of Rating scales}

As described in the 'Materials' section of this paper, the questions answered with rating scales were summarized into ten subscales (five each for the two characters in the video) and totalled into two overall scales (one for each character). The appropriate scale is labelled in brackets after each question in Appendix D. To examine possible differences between the rating for Ted and the rating for Christine, a within subject, repeated measure multivariate ANOVA was performed. As well scores wereaveraged across the characters in the video and a multivariate ANOVA was performed which included the 6 averaged scores.

Within subject effects. A $3 \times 3 \times 2$ (video by dysfunction by gender) multivariate ANOVA

examined the possible effects of the independent variables on the 5 subscale differences. A statistically significant main effect was observed for Gencer for the subscales of Mutual Acceptance (MA), Cooperation (COOP), Openness toward Partner(OPEN), and Nonverbal communication (NONV) and for the overall scale. Table 16 summarizes the results. Furthur when gender was isolated, this within subject effect of difference between ratings of the two characters held for both genders (see Table 17). The difference scores calculated for each scale indicated that the males perceived more difference between the two characdters than did the 
females, and rated Christine as more "mutually accepting", more "cooperative" more "open to her spouses ideas and feelings" and as using more "positive nonverbal behaviour" than the females did. Table 17 summarizes the results. 
Table 16. Repeated measures, within-subject effect of participants ratings of the two characters on the same variable.

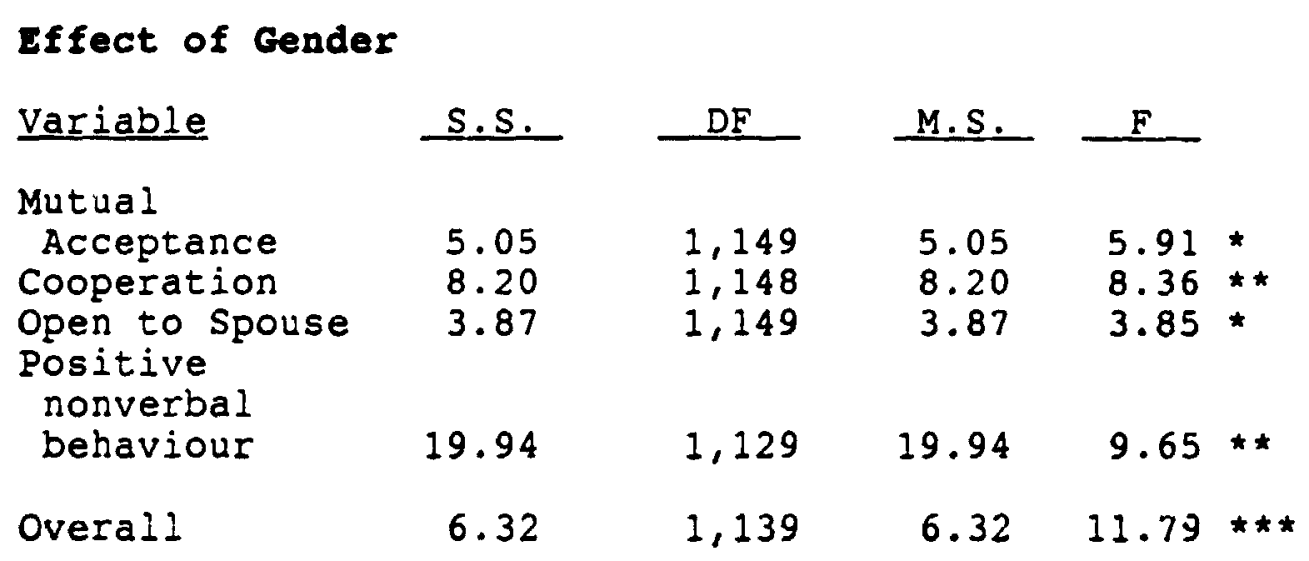

Effect within Males

Variable

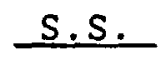

$\underline{D F}$

M.S.

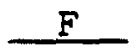

Mutual

Acceptance

Cooperation

27.32

1,74

27.32

$30.29 \star \star \star$

42.02

1,74

42.02

$45.00 \star \star *$

Open to Spouse

16.38

1,74

16.38

$15.82 * * *$

Positive

nonverbal

behaviour

34.64

1,61

34.64

$19.02 \star \star \star$

Overall

36.52

1,74

36.52

$68.54 \star \star \star$

Effect within Females

Variable

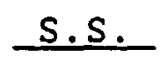

Mutual

\section{Acceptance}

Cooperation

Open to spouse

Positive nonverbal

behaviour

Overall
3.10

4.20

1.12

0.26

4.50
DF

M.S.

$F$

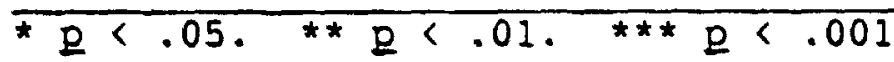


Table 17. Difference scores between participants ratings of Ted and of Christine on the same variables.

(More negative scores indicate Christine was rated higher).

\begin{tabular}{lll}
\hline Variable & Males & Eemales \\
\hline MA & -0.81 & -0.23 \\
COOP & -0.99 & -0.27 \\
OPEN & -0.66 & -0.16 \\
NONV & -1.09 & -0.13 \\
OVERALL & -0.95 & -.036 \\
\hline
\end{tabular}

Thus males rated the character Christine higher than Ted on each of these dimensions to a greater degree than did females.

The expected Main effect of video was observed as well (Pillais Trace $V=.266, E(10,220)=3.37, \mathrm{Q}(.001)$.

Analyses of Averaged Scores. Other than the expected main effect of video $(\underline{E}(10,220)=13.34, \underline{p}<.001)$, there were no significant main or interaction effects on any of the averaged scores.

The ambiguous video alone. As was planned, based on the results of the second pilot, the Ambiguous video was isolated and a $3 \times 2$ ANOVA was performed for both the difference scores and the average scores. There were no statistically significant results with the exception of the

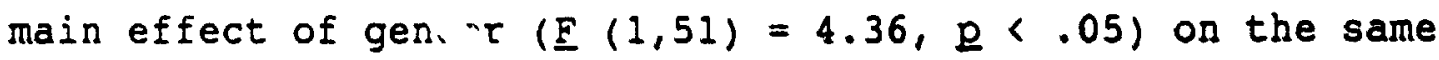
vairiables listed above. 
Analysis of the Open-ended Questions

In order to assess the open-ended questions of the questionnaire, a rating system was developed and two independent raters scored 40 of the questionnaires to obtain inter-rater reliabilities for these items. (see Appendix E for the scoring criteria). These questions included the recall of the items, presence of embellishment, recall of emotion, whether the participants judged one character as more at fault than the other, and finally a general attitude toward the communication evidenced in the video. All of these variables were taken from the participants free recall of the video. The next items tapped into a number of variables, for example, identifying factors which need improvement, or which represent "good" communication; the number and accuracy of the factors; prediction of the outcome of the relationship portrayed in the video; whether the participants stated that they were willing to implement the changes they suggested if they found themselves in a similar situation; and identification of factors which made the communication in the video successful or not (see the questionnaire in Appendix $D$ for the exact questions).

Inter-rater concordance (Cohen's Kappa) of these variables ranged from 0.23 to 1.00 . However, those variables with a Kappa statistic falling below 0.40 were discarded, as 0.40 has be- $n$ suggested as an acceptable minimum Kappa for concordance (Eleiss, 1981). After these 
variables were excluded, the resulting average Kappa was 0.63. The statistics for each variable are summarized in Tables 18 and 19. 
Table 18. Concordance rates of the two independent raters for the recall of events in the video.

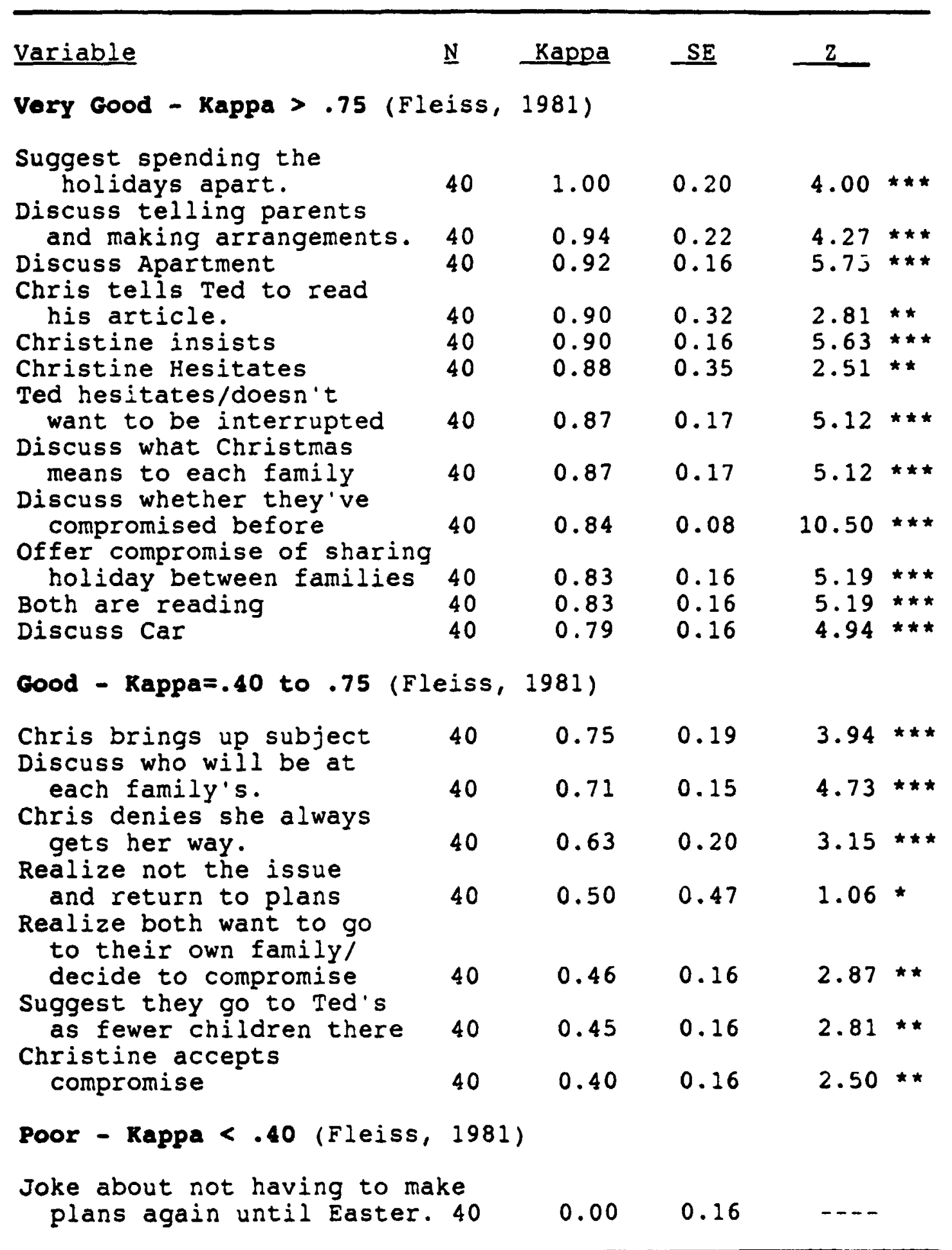

$\star \star \star \mathrm{p}<.001 . \star \star \star \mathrm{g}<.01 . \star \mathrm{g}<.05$ 
Table 19. Concordance rates of the two independent raters for the open-ended questions.

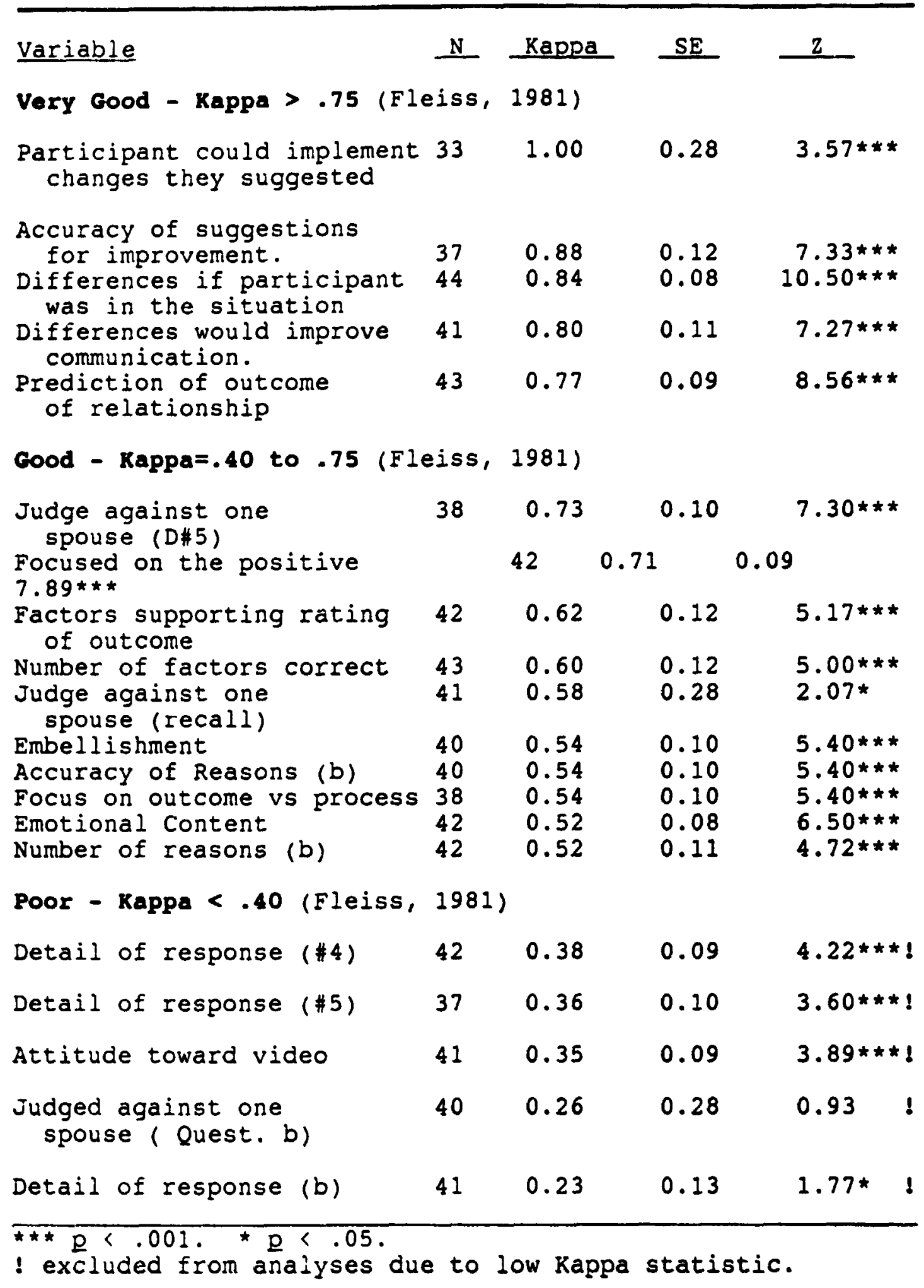


Recall of Items. $x^{2}$ statistics were completed for each of the twenty items scored for the section dealing with free recall of the video. While six items differentiated levels of dysfunction within a particular video, low phi coefficients were also observed which suggested no meaningful relationship.

The 3 (video) $\times 3$ (dysfunction) $\times 2$ (gender) MANOVA on the total number of items recalled was also explored. A main effect of video was observed $(E(2,137)=5.63$, $\mathrm{E}<$ $.004)$. The planned comparison of means revealed that while the total items recalled did not differentiate between the Good video and the Ambiguous video, both of these conditions resulted in a greater number of items recalled than did the Bad video ( $t(152)=3.38, \mathrm{~g}<.001$ and $\underline{t}(152)=2.57, \mathrm{p}<.01$ ) respectively. As with exposure to counselling environments, this represents a potential confound in this study.

Open ended Questions. The variables summarized in Table 19, were observed to have little intercorrelation and therefore were entered into a multivariate $3 \times 3 \times 2$ (video by dysfunction be gender) ANOVA to test for treatment effects. A trend toward significance was observed for the main effect of Gender (Pillais Trace $V=.271, E(18,81)=$ $1.67, \mathrm{R}(.10)$. Univariate $\mathrm{F}$-tests revealed differences on five variables, specifically, males judged against one 
spouse more often, predicted a more positive outcome for the relationship, reported fewer differences if they were in the situation themselves, had fewer reasons for why the communication was good or bad, and were less accurate in these reasons than the females. These results are summarized in Table 20.

Table 20. Univariate F-test of the main effect of gender

\begin{tabular}{|c|c|c|c|}
\hline Variable & $\begin{array}{c}\text { Mean } \\
\text { Male }\end{array}$ & Female & $F(1,98)$ \\
\hline $\begin{array}{l}\text { Judged against } \\
\text { one spouse. }\end{array}$ & 2.11 & 1.42 & $6.59 \star \star$ \\
\hline $\begin{array}{l}\text { Prediction of } \\
\text { outcome of } \\
\text { relationship. }\end{array}$ & 2.40 & 2.09 & $6.11 * \star$ \\
\hline $\begin{array}{l}\text { Differences if } \\
\text { participant in } \\
\text { situation. }\end{array}$ & 3.28 & 3.60 & $3.82 \star \star$ \\
\hline $\begin{array}{l}\text { Number of reasons } \\
\text { why communication } \\
\text { was Good/Bad. }\end{array}$ & 1.64 & 1.97 & $5.73 *$ \\
\hline Accuracy of reasons & 1.26 & 1.70 & $5.73 *$ \\
\hline
\end{tabular}

Although the multivariate ANOVA was not statistically significant ( 1.28,n.s.), the univariate F-tests of the effect of Dysfunction were examined for possible leads for future research (Tabachnik \& Fidell, 1983). Two variables showed a 
main effect due to dysfunction. The first variable was a ratio of the number of reasons why the communication was good/bad divided into the number of reasons correct. The second variable dealt with whether participants focused on the negative or the positive. Table 21 summarizes the results.

Table 21. Group means and univariate F-tests for the main effect of dysfunction.

Group $\frac{\text { Accuracy of Reasons }}{\text { (percentage correct) }}$
Focussed on outcome process, or both

Functional

0.83

3.64

Moderate

0.74

2.78

Dysfunctional

0.89

3.65

$\underline{E}(2,98)$

$3.22 *$

$5.61 \star *$

$\star \star 2<.01 . * \mathrm{Q}<.05$.

The Ambiguous video alone. When the Ambiguous video was isolated and examined, no statistically significant results were observed. However, despite the multivariate ANOVA's lack of significance, the univariate F-tests were examined to identify potential areas for future research (Tabachnik \& Fidell, 1983). The variation among levels of dysfunction for the "number of reasons why the communication in the video was good or bad" showed a trend toward significance $(\underline{F}(2,36)=2.84 \mathrm{D}<.10)$ which may suggest that the Moderate group listed more reasons than either the Functional or the Dysfunctional groups. 


\section{Discussion}

Generally speaking, no clear patterns were observed in this study. It is therefore difficult to assess at this point what effect communication and general functioning have on people's perception of communications. Some directions for future research are indicated however, and these shall be explored. Before this is done, it is important to acknowledge that the results here must be qualified with the fact that there were two confounding variables in this study. First, those participants who observed the Good video, reported more exposure to counselling environments than did participant who viewed the other two videos. It is not possible to determine from the present data which of three possibilities is more likely: whether exposure to the good communication video increased recall/reporting of counselling experience; whether the other two videos reduced recall/reporting of counselling experience; or whether the random sampling did not accomplish the intended equal distribution of this variable. Second, the total number of factors recalled varied across the videos, in that the participants recalled more events from the Good and Ambiguous videos than from the Bad video. This suggests that the three videos were not as 'parallel' as had been thought. Future studies should pilot total items recalled to ensure that participants recall the events in each video equally. In addition, the limited generalizability of the 
premeasure (FAD) to populations other than white, middle class traditional families, denotes added caution to the interpretation of the results. With these qualifications in mind, the results will now be discussed.

Overall Rating of the Quality of Communication in the video. When overall ratings were examined, the video by dysfunction interaction observed in the second pilot study disappeared. However, the planned comparison of the Functional group vs the Dysfunctional group within the Ambiguous video did show there to be differences in these two ratings. The Dysfunctional group rated the communication as more negative than did the Functional group. When this is considered in combination with the reasons why the communication was Good/Bad and the accuracy of the same, it can be seen that both groups provided about the same number of reasons $(\underline{M}=1.42, \underline{M}=1.50$ respectively), and both were relatively accurate in their answers $(\underline{M}=.84$ and $\underline{M}=.82$ respectively $)$. Since differences in ratings do not reflect differences in number of observations, or in accuracy, it is possible that any differences in overall ratings could be the result of differences in perception. The Dysfunctional group may have been more receptive to, and influenced by the negative aspects of the interaction whereas the Functional group may have been equally receptive to and influenced sy both. A 
future study could look at this in more detail by measuring recall of video, overall ratings, reasons for rating and accuracy again and then to clarify this, asking questions about what parts of the interaction influenced the participants ratings. The present data suggest that the Dysfunctional group would report being influenced by the negative events more often than the Functional group. It could also be hypothesized that the Functional group would report a more balanced selection (both Good and Bad).

Within the Ambiguous condition, a trend was observed which suggested that the Moderate group reported a greater number of reasons why the communication in the video was good or bad, than did either the Functional or the Dysfunctional groups, although no differences were observed in terms of accuracy. Perhaps those individuals with communication problems alone focus on more detail when the communication is ambiguous. Future research could isolate ambiguous types of communication for study, and look closely at the detail of the responses across levels of dysfunction to find out if there are differences in the types of reasons reported, or in how elaborate the responses are.

? lother trend observed in the data involved response to the question "What factors made the interaction successful or not". Here, the ratio of the "number of correct reasons" over the "number of reasons" differed across levels of dysfunction. In this case, the Functional and Dysfunctional 
groups were more accurate than the Moderate group. This is interesting in that it appears that dysfunctional communication combined with good general functioning predicts less accuracy in judging factors of success that do either dysfunctional or functional levels of both these variables. It may be that exposure to both dysfunctional communication and poor general functioning in the family breeds individuals who are more sensitive to the situation and the contributing factors. Dysfunctional communicaticn alone, however may disadvantage a person in this area. Perhaps when this one area of disadvantage is not balanced with more global experionce in negative factors family functioning, the person is left wits an impediment in terms of judging success of an interaction. It is interesting to note that this applies only to judging the "success" of the interaction. "hen judging whether the ccinmunication was good or bad, all three groups were equally accurate. Future studies could focus on this area of discrepancy, looking at how the three groups rate interactions with various levels of success, success being defined as meeting most of the criteria listed in Table One as well as coming to a decision which is a compromise and is acceptable to both parties involved.

The third finding of this study parallels the results discussed above. When participants were asked to explain why the interaction was successful or not they were rated on 
whether they focused on either the outcome, the process of both. Both the Flnctional and Dysfunctional groups focused on both process and cutcore, whereas the Mrderate group focused more on the outcome. When this finding is looked at in combination with the previous findings, it siggests that poor communication skills alone in the family may result in poor judgment of communication processes, thus "success" is measured not through process but solely through outcome. It appears that here again global dysfunction in the family moderates the effects of dysfunctional communication. As with the Functional group, those individuals in the Dysfunctional group focussed on both outcome and process as a means to judge the success of an interaction. As mentioned above, this may be due to increased exposure to dysfunctional interaction and thus more experience and/or expertise in assessing interpersonal situations.

\section{Effects of Gender}

Gender was included as a variable due to the vast literature looking at differences in language and communication between the genders (e.9., Hyde \& Rosenberg, 1980; Mayo \& Henley, 1981; Nadler, Nadler \& Todd-Mancillas, 1987; Stewart \& Ting-Toomey, 1987). Although most research deals with generating communication and interpreting communication directed at oneself, as opposed to being an objective observer, it was thought that males and females 
might interpret and rate the videos differently.

In fact, differences were observed. While both genders perceived differences between the two characters on the video, males judged against one spouse more often than females, they predicted a better outcome for the relationship than did females, they reported fewer differences between what they observed and what they would have done themselves in the same situations, and they reported fewer reasons why they rated the interaction as Good or Bad as well as being less accurate in their reasous. This implies that females and males do perceive the same stimuli differently regardless of the quality of communication in the interaction. Thus, any future research should include the variable of gender in the experimantal design.

\section{Clinical Implications.}

More research is necessary before any conclusions can drawn, and this section should also be prefaced with the reminder of the somewhat limited generalizability of this data. The results of this study, may only generalize to individuals from white, middle class, traditional families. However, the present data indicates three general trends which could be pursued.

1) Males and females react differently to the same communication stimuli, regardless of the quality of the 
communication or the level of familial dysfunction. Any therapeutic intervention should keep these potential differences into account.

2) The Moderate group appears to the most "at risk" in this sample in terms of future relaiinnships. They are not as accurate in judging what is or is not a successful interaction which may hinder problem solving in their own relationships. Since they focus mostly on outcome, rather than interaction, therapeutic intervention should focus on ilelping them to be aware of the process (how was the decision reached) instead of only outcome(who wins or loses). Furthur, with interactions involving ambiguity, they are more detailed in their responses as to why the communication was good or bad.

3) The Dysfunctional group may focus more on negative aspects of communication when the stimulus in ambiguous. Therapeutic intervention for these individuals may need to focus more on helping these individuals to achieve a more balanced view of an interpersonal interaction. In other words the individual should be encouraged to acknowledge what was good as well as what was bad. These results may represent a reporting bias in that they may notice both but only report the problematic issues. In terms of future relationships, this may be problematic in that positive aspects of the relationship may not be reported to the spouse along with the negative aspects creating a 
confrontational environment which impedes problem-solving. Helping the "dysfunctional" individual to be aware of express the positive aspects of interpersonal interactions may prevent this potential confrontational atmosphere.

In summary, while a few confounds exist, and no definitive answer can be arrived at solely from the results of the present study, it appears that familial dysfunction (specifically dysfunctional communiction) may be related in some way to perception of communication and this could have implications for the success of future relationships of young adults emerging from these families. Identifying communication and general functioning problems in an individual's family could point to specific potential problem areas which, if addressed early, may avoid serious problems in their own intimate relationships. It also appears that both communication and general functionaing levels should be looked at in that different combinations may imply different potential problem areas.

To investigate more specifically how future Ielationships may be affected, future research should first attempt to focus on the potential areas of difficulty identified in this study, and obtain more detail with regard to the individual's perceptions and the thought processes involved. Since a more quantitative approach was used in the present study to identify potential problem areas, a 
qualitative approach lould likely be the most informative means to supplement the understanding of the processes involved.

Secondly, the quality of these peoples present and past relationships should be explored more effectively than was possible in this study. Examples of the problems hypothesized above could be noted and trends across levels of dysfunction observed to see whether or not these projected deficits and problems actually exist and are problematic in their current relationships. While the results of this study are far from definitive, as an exploration of possibilities, it does lend direction and focus to future research in the area of familial dysfunction and its effects on perception of communication in young adults emerging from these families. 
PAGINATION ERROR.

TEXI COMPLETE.

NATIONAL LIBRARY OF CANADA.

CANADIAN THESES SERVICE.
ERREOR DE PAGINATION.

LE TEXTE EST COMPLET.
BIBLIOTHEQUE NATIONALE DU CANADA. SERVICE DES THESES CANADIENNES. 
APPENDIX A 
Name Age Sex $M / F(c i r c l e$ one)

FAMILY PERCEPTIONS

This questionnaire asks about your familir (parents \& siblings). By "family" we mean the prople you consider your family; in other words, the people you $;$ ? "emotionally related" to. For example, this could be a bic_ogical family, a foster family, or an adopted family.

please read each statment and indicate whether or not you agree that it is a relatively accurate description of your family. Please use the following rating scale:

$$
\begin{array}{cccc}
1 & 2 & 3 & 4 \\
\text { Strongly Agree } & \text { Agree } & \text { Disagree } & \text { Strongly Disagree }
\end{array}
$$

Remeber, your responses are confidential, so please answer as honestly as you can. Write the number of your response in the space to the left of each statement.

\section{Response Statement}

1) We usually act on our decisions regarding family problems.

2) When someone is upset, the others know why.

3) When you ask someome to do something, you have to check that they did it.

4) We are reluctant to show our affection for each other.

5) If someone is in trouble, the others become too involved.

6) We don't know what to do when an emergency comes up.

7) Planning family activities is difficult because we misunderstand each other.

8) After our family tries to solve a problem, we usually discuss whether it worked or not.

9) You can't tell how a person is feeling from what they are saying.

10) We make sure members meet their family responsibilities.

11) Some of us just don't respond emotionally. 
$\begin{array}{cccc}1 & 2 & 3 & 4 \\ \text { Strongly Agree } & \text { Agree } & \text { Disagree } & \text { Strongly Disagree }\end{array}$ Response statement

12) You only get the interest of others when something is important to them.

13) You can easily get away with breaking the rules.

14) In times of crisis, we can turn to each other for support.

15) We Iesolve most emotional upsets that come up.

16) People come right out and say things instead of hinting at them.

17) Family tasks don't get spread around enough.

18) We do not show our love for each other.

19) We are too self-centred.

20) We know what to do in an emergency.

21) We cannot talk to each other about the sadness we feel.

22) We confront problems involving feelings.

23) We are frank with each other.

24) We have trouble meeting our bills.

25) Tenderness takes second place to other things in our family.

26) We get involved with each other only when something interests us.

27) We have no clear expectations about toilet habits.

28) Individuals are accepted for what they are.

29) We try to think of different ways to solve problems.

30) We don't talk to each other when we are angry.

31) There's little time to explore personal interests.

32) We express tenderness. 


$$
\begin{array}{cccc}
1 & 2 & 3 & 4 \\
\text { Strongly Agree } & \text { Agree } & \text { Disagree } & \text { Strongly Disagree }
\end{array}
$$

\section{Response Statement}

33) We show interest in each other when we can get something out of it personally.

34) We have rules about hitting people.

35) We avoid discussing our fears and our concerns.

36) When we don't like what someone has done, we tell then.

37) We discuss who is to do household jobs.

38) We cry openly.

39) Our family shows interst in each other only when they can get something out of it.

40) We don't hold to any Iules or standards.

41) We can express our feelings to each other.

42) If people are asked to do something, they need reminding.

43) Even though we mean well, we intrude too much into each other's lives.

44) If the rules are broken, we don't know what to expect.

45) There are a lot of bad feelings in the family.

46) We are able to make decisions about how to solve problems.

47) We are generally dissatisfied with the family duties assigned to us.

48) Anything goes in our family.

49) We don't get along well together.

50) We feel accepted for what we are.

51) There are rules about dangereous situations.

52) Making decisions is a problem for our family.

53) We confide in each other. 
APPENDIX B 
Ted and christine are 23 years old. They both graduated from university last year and are working in their respective fields. They have been seeing each other for 8 months and living together for the last four months. They have discussed marriage but have decided to wait until they are a little more financially stable.

It is presently late october, and they need to decide what they are doing for the Christmas holidays. Their parents live in different cities, so a choice must be made. 
CHRISTINE: Ted, can we talk?

TED: Sure, I just want to finish this article.

CHRISTINE: Well, could you read it later? I want to decide about what we're doing for Christmas, and it's really bugging me.

TED: Oh well okay. I'll finish it later. Why do we have to discuss it now anyway? Christmas is two months away.

CHRISTINE: Well, families have to know Ted. Travel arrangements need to be made. If it were up to you, we'd still be deciding on Christmas Eve.

TED: I suppose, so what's left to discuss?

CHRISTINE: Well, my parents really want us to come there. I've told them all about you and $I$ talk about you all the time so they really want to meet you. Christmas-time is a special time of year for us, and they really want you to be a part of it.

TED: Yeah, I remember talking about that when we first met. You said the whole family gets together for Christmas and New Year's?

CHRISTINE: Uh huh.

TED: It sound great. Christmes is importent to my family too. It's one of the few times we all get together. I'd like you to be a part of that and meet everybody.

CHRISTINE: Well, it seems both of ous families are important to us.

TED: Well, one solution is that you could spend Christmas with your family, and I'll spend it with mine.

CHRISTINE: Don't you want to spend Christmas together? I mean I thought we'd be together at Christmas, at least I assumed. . .

TED: No, I want to be with you Christine, I want to spend Christmas together. It's just a difficult decision. Both of our families want us with them, so what do we do? 
CHRISTINE: Well, I want to spend Christmas with you too. We'll just have to figure something out.

TED: Who all is going to be at your parents for Christmas this year?

CHRISTINE: Oh, the whole family's going to be there. Richard and his wife, and Sarah's even coming home.

TED :

Oh Sarah tı .! That's great! My brother Peter's going to be home, but I don't know it the rest of the family will be this year.

CHRISTINE: I'd really like to meet peter. I've heard so much about him.

TED:

Yeah, we're really close. It would be great to see him again.

CHRISTINE: Well, wa have compromised before.

TED: That's true. We managed to decide on this place, but then there was the car.

CHRISTINE: What's wrong with the car?

TED: Nothing's really wrong with it, jt's just that we really only looked at the ones yju wanted.

CHRISTINE: You should have said something if you wanted to see one.

TED: It's not that important. My point is that we just haven't always compromised. I like the car. It was a good choice.

CHRISTINE: Well, I told you you'd get used to red.

TED: Sure . . so let's decide this holiday thing.

CHRISTINE: Well. . all my family's going to be there but it looks like only peter is going tn get home to your folks' place.

TED: Yeah. It will be kind of lonely for them. They're used to having all the kids around.

CHRISTINE: Well, we should probably spend Christmas with them. After all, you'il get to see Peter and I know how much you miss him.

TED: It doesn't have to be either/or. . 
CHRISTINE: What do you mean?

TED: Well, if you're sure you don't mind, we could spend Christmas at my parents, I know they'd be thrilled, but then we' 11 go to your parents' for New Years. Say on the day after Boxing Day.

CHRISTINE: O.K. That would be great! Because Richard and Sarah would still be there. You could meet them both.

TED: Are you sure that's 0.K. with you? Your parents won't be upset or anything?

CHRISTINE: Oh, they'li understand. They'll have Richard and Sarah anyway.

TED: If you're sure, that's great! My parents will ie really pleased. And next year we'll reverst the process.

CHRISTINE: O.K. That sounds fair. . Thanks. What I'll do is call tomorrow and make the reservatiors, then I'll call my parents and explain what's happening, and then we'II see what happens. You should give yours a shout too.

TED: Yeah, I will. Thanks for understanding.

CHRISTINE: That's what I'm here for. Anyways, read your article, we only have until Easter until we have to do this again. 
CHRISTINE: Ted, we need to talk.

TED: I just want to finish this article.

CHRISTINE: We have to decide what we're doing for Christmas.

TED: $\quad 0 . K$. I'll read it later. Why do we have to make plans now anyway? Christmas is two months away!

CHRISTINE: Families need to know. We have to make travel arrangements. If it were up to you, we'd still be deciding on Christmas Eve.

TED: Well, what's left to discuss?

CHRISTINE: Well, my parents really want us to come there. I've told them all about you and I talk about you all the time. Christmas is a special time for us and they want you to share it.

TED:

Well, it's special to my family too.

It's one of the few times we all get together. I'd like for you to be a part of that and meet everybody.

CHRISTINE: Well, it seems our families are important to us.

TED: Well, one solution is that you could spend Christmas with your family and I'll spend it with mine.

CHRISTINE: Well, if that's what you want.

TED: What do you mean by that? I said it was one soluticn Christine.

CHRISTINE: If it's your cnly solution, then obviously you don't want to spend Christmas with me.

TED:

How did you get that? I want to spend Christmas with you.

CHRISTINE: It doesn't sound like it.

TED:

Nell, I mean it. I want us to be together at Christmas. It's just tilat both of our families want us with them, and it's a difficult decision.

TED :

Who's going to be at your parents this year? 
CHRISTINE: Well, the whole family's going to be there. Richard and his wife, and Sarah's even coming down.

TED: That'll be nice. Peter's the only one who's gonna be home to my place this year.

CHRISTINE: I'd like to meet Peter. I've heard so muct about him.

TED: $\quad$ Yeah, it would be good to see him again.

CHRISTINE: Well, We have managed to compromise before...

TED: When have we compromised?

CHRISTINE: Pardon?

TED: $\quad$ Seriously. We usually end up doing things your way. We live here because you wanted to. We bought the car that you wanted. I think it's my tura.

CHRISTINE: You loved this place. We bought the car together and we decided together.

TED: $\quad$ The only cars we even looked at were the ones you

gushed wanted. You gave me no real choice. And you over this place so much, I knew you loved it. I I wanted to make you happy.

CHRISTINE: That was your choice. You should have said something.

TED: I guess this really isn't the issue.

CHRISTINE: No, I guess not.

TED: So, who's parents is it going to be? Let's just decide this thing.

CHRISTINE: Look, I don't want to argue. Everyone's going to be at my parent's place but it looks like Peter's the only one at your folk's place.

TED :

used

Yeah, it will be kinda lonely for them. They're to having all the kids around.

CHRISTINE: Then we should probably spend Christmas with them. 
TED: I don't want you to be unhappy.

CHRISTINE: No. I'm fine.

TED: Well, if you're sure you don't mind, we could spend Christmas at my parents place - I know they'd be thrilled - but then we'll go to your parents for New Years.

CHRISTINE: Well . . Richard and Sarah would still be there. you'd still get to see them both.

TED :

Are you sure that would be $0 . K . ?$ your parents won't be upset?

CHRISTINE: Oh, I' 11 make them understand. . They'11 still have Richard and Sarah.

TED: What about you? There's no point in going if you're going to be too upset to enjoy yourself.

CHRISTINE: No . . don't worry about it. I can phone them right?. . and I'Il see them at New Years. I'll be $0 . k$.

TED: Well, if you're sure, that's great. My parents will be really pleased.

CHRISTINE: Well, at least that's figured out. I'll call tomorrow and make the reservations. Then I'il call my parents and iry to explain our plans. I hope they understand at least.

TED: Oh, I'm sure they will Christine.

CHRISTINE: I hope so.

TED: Well. I'm glad that's finally settled.

CHRISTINE: You bet. Anyway, read your article. We don't have to worry about this again until Easter. 
CHRISTINE: Ted, can we talk for a minute?

TED: Hold on, I'm reading something.

CHRISTINE: We have to decide what we're doing ror Christmas.

TED: $\quad$ You know I want to finish this article. You never let me read anything from start to finish.

CHRISTINE: You can read it later.

TED: We can discuss this later.

CHRISTINE: No. I want to discuss it now.

TED: Fine. Talk.

CHRISTINE: Look, it's just that we have to make plans, that's all.

TED: Why do we have to make plans now? Christmas is two months away!

CHRISTINE: Families have to be told. We have to make travel arrangements. If it were up to you we'd be deciding on Christmas Eve.

TED: We have been through this so many times... .

CHRISTINE: No. Ycu've been through it. We haven't decided a thing.

TED: What's left to discuss?

CHRISTINE: My family really wants us to come. I've told them all about you. I talk about you all the time and they want to meet you. I mean, Christmas-time is a special time for us and they just want you to be a part of it.

TED: Well, it's important to my family too. You don't care about that. All you care about is your family. My family is just as important to me as yours is to you, but you don't care about that.

CHRISTINE: Me? You don't accept how important my family is to me!

TED: Fine. You spend Christmas with your family and I'll spend Christmas with my family. 
CHRISTINE: That's what I thought.

TED: What?

CHRISTINE: Nothing.

TED : Christine...

CHRISIINE: No, what's the point. I can't tell you anything. $I \cdot m$ not going to change the way you feel.

TED: Oh Christ Christine, what the Hell are you talking about now?

CHRISTINE: I've just realized what this is all about. You don't want to spend Christmas with me. You're using your family as an excuse for not spending Christmas with me.

TED: Yes, I want to spend Christmas with you.

CHRISTINE: Yeah. It sure sounds like it.

TED: What the Hell do you want from me? The World? You want everything your way. I'm just supposed to dismiss what I feel and do everything your way.

CHRISTINE: It's just very obvious to me that you don't want to spend Christmas with me and you just don't want to admit it.

TED: Stop trying to read my mind. I said I wanted us to be together at Christmas. Just accept that.

CHRISTINE: Fine. Whatever.

What do you want to do for the holidays?

TED: Why can't we do it my way for a change?

CHRISTINE: For a change? We're always doing things your way.

TED: Oh. Yes that's right. We are. Then why is your family more important than mine?

CHRISTINE: My family is not more important. Why don't you ever listen? It's just a special time of year for us. Richard and his wife are going to come down, and Sarah's even coming home. They just want you to share with them. 
TED: Yes, well, my family may not be the perfect family that yours is, but it's important to us. Peter's the only one even going home this year.

CHRISTINE: Peter again. I think you care more about him than you do me.

TED: I'd just like to see him again. . Why can't you ever do anything my way?

CHRISTINE: Pardon?

TED: $\quad$ Nothing.

CHRISTINE: Oh. Great.

TED: Well, you never listen anyway.

CHRISTINE: Well, if you had anything reasonable to say, maybe I'd listen.

TED: I feel like we always do everything your way. We live here because you wanted to. We bought the car you wanted. It's my turn.

CHRISTINE: You loved this place. And we bought the car together, Ted. We happened to have decided together.

TED: The only cars we even looked at were the ones you wanted. You gave ne no real choice. And you gushed over this place so much, I knew that you loved it. I wanted to make you happy. So sue me for caring.

CHRISTINE: That was your choice.

TED: Oh yes. That's right. Once again, it's never your fault. It's always my fault. So, who's parents is it going to be? Let's decide the goddam thing and be done with it.

CHRISTINE: Oh, I don': care. We can go to your parents' place. But I'm going to mine for New Years.

TED: I don't want you going to my parents' if you're going with an 'attitude'.

CHRISTINE: You're the one with the attitude. You won't discuss it. Look, I'm tired of arguing. We'll do whatever you want. 
TED: Maybe I won't discuss anytring because you mever listen.

CHRISTINE: There's not much to listen to.

TED: Love you too.

CHRISTINE: Lay off Ted. I'll make the reservations, I'll call my folks and I'll try to figure out what to say. I'm not looking forward to it.

TED: Oh, I'm sure they'll cope. It's not like you're deserting them. They'll still have Richard and Sarah.

CHRISTINE: You just don't understand.

TED: $\quad$ No. I guess I don't.

CHRISTINE: Oh just read your precious article. Thank God we have until Easter before we have to go through this again. 
APPENDIX C 
1) Please describe what you recall were the significant events of the video. Include what you think about how each member of the couple might have felt about how things were going during the interaction.

When couples discuss an issue many different factors may be involved; how they talk to each other, how they listen to each other, their tone of voice, their feelings toward each other, and how pleasing the outcome is to each of them. With this in mind, please think about the whole discussion you've just heard and answer the following questions.

2) On the following scale please rate your overall impression which you have of the communication patterns in the tape you just heard.

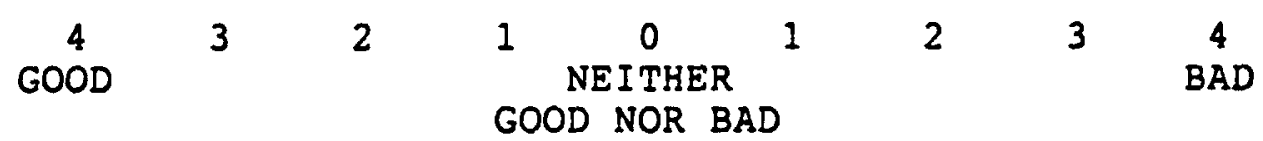

3) Each of the partners probably had some feelings about the outcome of their conversation. Please indicate here how you think Ted mught have felt.

Ted:

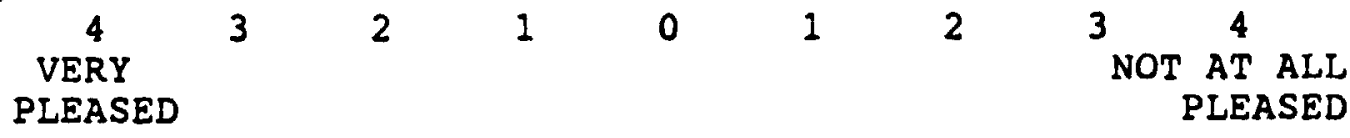
felt:

Now please indicate how you think christine might have

Christine:

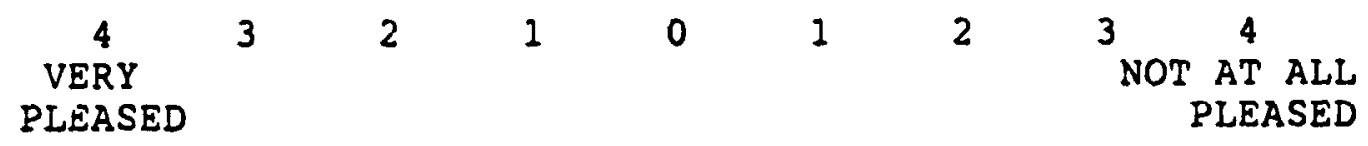

Was the outcome which the couple reached a good one, in your view? 
4) How come? -- (what do you think most influenced your rating of the outcome)?

5) If you feel that the couple's communication pattern could be improved, in what ways would you suggest that one or the other or both of the partners might change?

a) Did the members of the couple validate each other's opinions?

In other words, did they accept the other's points as valid even if they disagreed with them?

TED SHOWED:

$\begin{array}{ll}0 & 1 \\ \text { No } & 2 \\ \text { Acceptance }\end{array}$

4

56
$\begin{array}{lll}6 & 7 & 8\end{array}$
Complete Acceptance
CHRISTINE SHOWED: $\begin{array}{lllllllll}0 & 0 & 1 & 2 & 3 & 4 & 5 & 6 & 7 \\ \text { No } & & & & & & & \text { Complete }\end{array}$ Acceptance Acceptance

b) Did the couple convey to you the feeling that they understood each other?

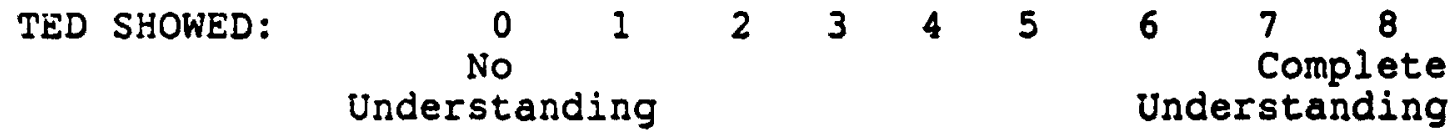

CHRISTINE SHOWED: $\begin{array}{cccccccc}0 & 1 & 2 & 3 & 4 & 5 & 6 & \begin{array}{c}7 \\ \text { Nomplete } \\ \text { Understanding }\end{array} \\ \end{array}$

Understanding Understanding 
a) Did they criticize each other?

$\begin{array}{lllllllll}\text { TED SHOWED: } & \begin{array}{l}0 \\ \text { No } \\ \text { Criticism }\end{array} & 1 & 2 & 3 & 4 & 5 & 6 & \begin{array}{c}7 \\ \text { A lot of } \\ \text { Criticism }\end{array} \\ \text { CHRISTINE SHOWED: } \begin{array}{c}0 \\ \text { No } \\ \text { Criticism }\end{array} & & 2 & 3 & 4 & 5 & 6 & \begin{array}{c}7 \text { A } 8 \text { of of } \\ \text { Criticism }\end{array}\end{array}$

d) Did they react in an clearly negative manner or a cluarly positive manner to what was being said by the other?

TED SHOWED:

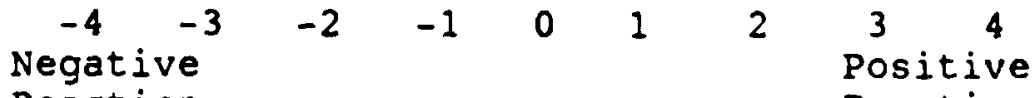

$$
\begin{aligned}
& \text { Reaction Reaction }
\end{aligned}
$$

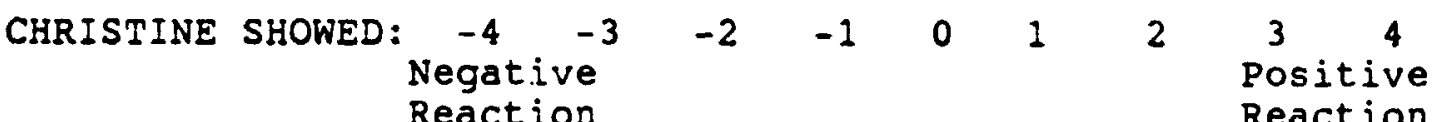

e) Each member of the couple could have treated this situation more on the side of "compromise" or more on the side of "win or lose". Please indicate which position each member took.

TED:

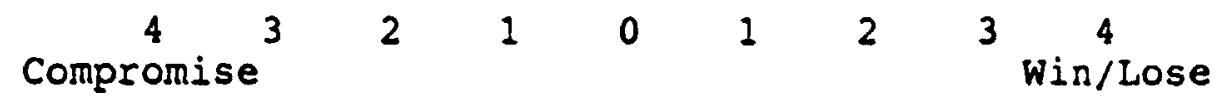

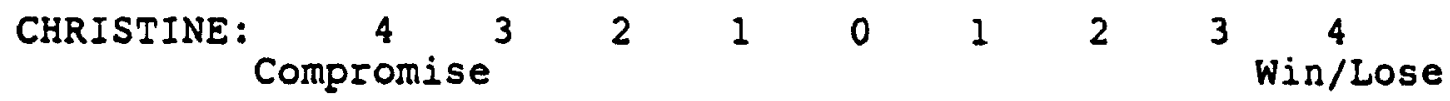

f) Was the communication of each partner more on the side of clear and direct or more on the side of vague and indirect?

TED:

$\begin{array}{lllllllll}\begin{array}{l}\text { Vague/ } \\ \text { Indirect }\end{array} & 3 & 2 & 1 & 0 & 1 & 2 & 3 & 4 \\ \text { clear/ } \\ \text { Direct }\end{array}$

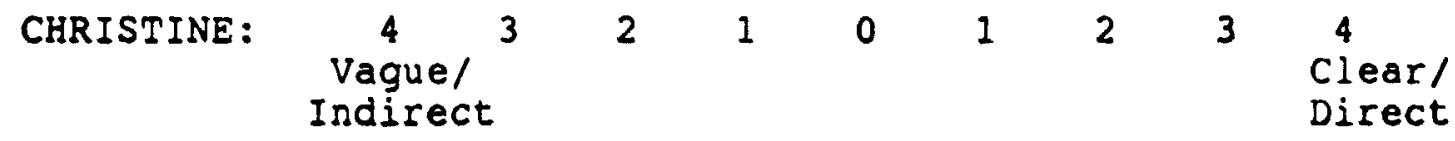


g) Was each partner open to communication from the other or did they tend to shut out the other?

$\begin{array}{lccccccccc}\text { TED: } & \begin{array}{c}0 \\ \text { Open }\end{array} & 1 & 2 & 3 & 4 & 5 & 6 & 7 & 8 \\ \text { CHRISTINE: } & \begin{array}{c}0 \\ \text { Open }\end{array} & 1 & 2 & 3 & 4 & 5 & 6 & 7 & \begin{array}{c}8 \\ \text { Closed }\end{array}\end{array}$

h) Was each partner likely to accuse the other or to work with the other to find a solution?

TED :

$$
\begin{array}{ccccccccc}
0 & 1 & 2 & 3 & 4 & 5 & 6 & 7 & \begin{array}{c}
8 \\
\text { Working } \\
\text { Accusing }
\end{array}
\end{array}
$$

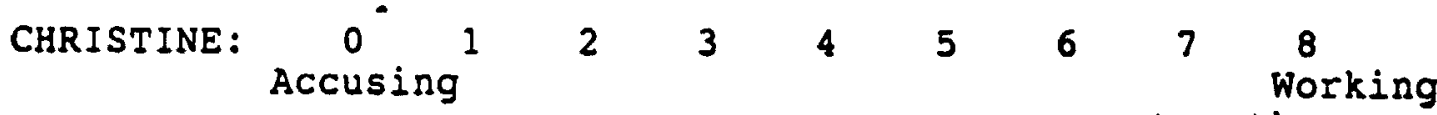
together

i) Was each partner likely to "blame" the other for their predicament or for any difficulty they had in solving - the problem?

TED:

$\begin{array}{ccccccccc}\begin{array}{c}\text { Blamed } \\ \text { Christine }\end{array} & 1 & 2 & 3 & 4 & 5 & 6 & \begin{array}{c}7 \\ \text { Did not blame } \\ \text { Christine }\end{array}\end{array}$

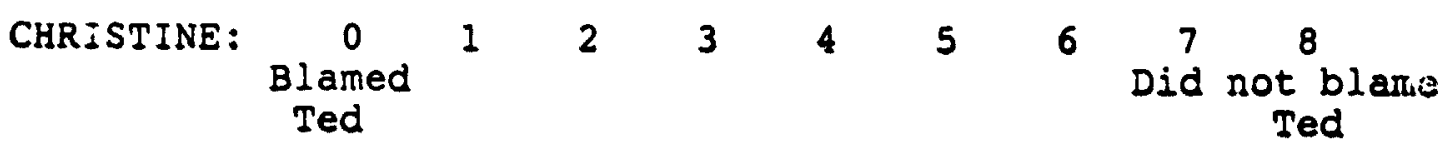


APPENDIX D 

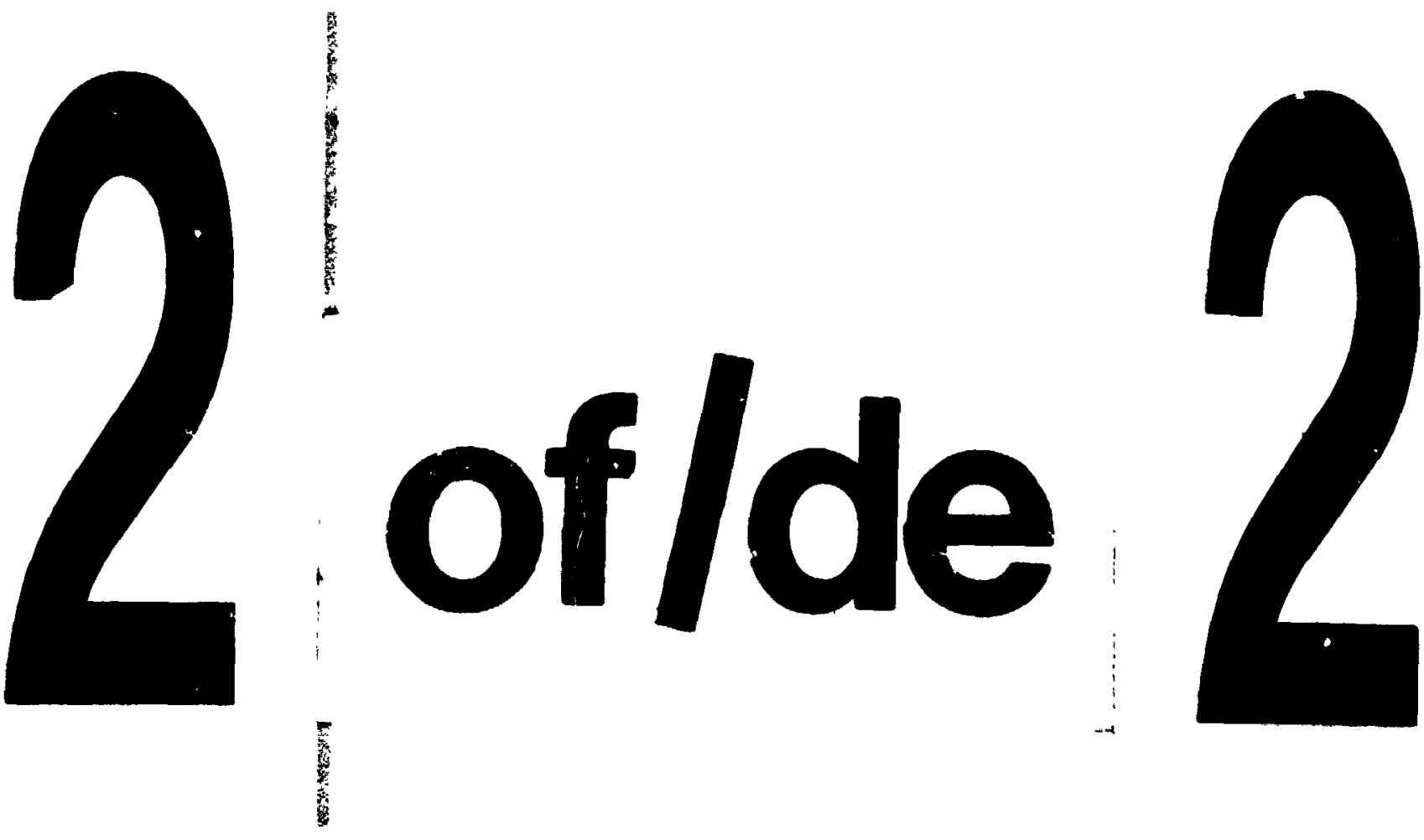

PM-1 31\%"x4" PHOTOGRAPHIC MICROCOPY TARCET NBS 1010 a ANSI/ISO \#2 EOUIVALENT

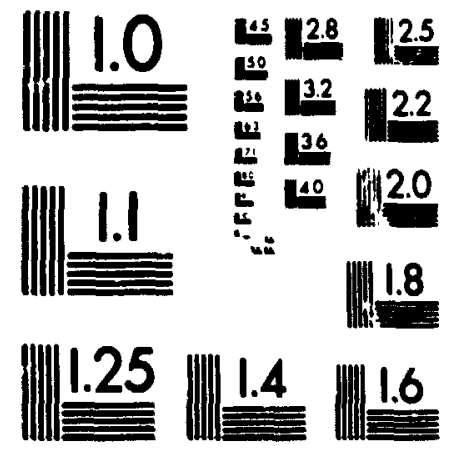


In this questionnaire you are going to be asked several kinds of questions. The instructions are different for some of the scales. Please read the instructions carefully for each set of questions. Your care in following these instructions will be appreciated.

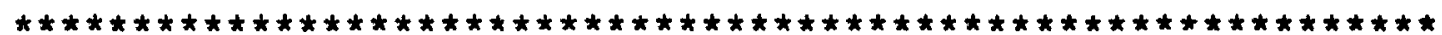


1) Please recall the events of the video you just saw and describe as much of what happened as possible. For each of the events you remember, please give me your guess as to how each member of the couple might have been feeling about their talk, how they spoke to each other, and how things went during their talk. (Use the back if necessary). 
When couples discuss an issue many different factors may be involved; how they talk to each other, how they listen to each other, their tone of voice, their feelings toward each other, and how pleasing the outcome is to each of them. With this in mind, please think about the whole discussion you've just heard and answer the following questions. Your answers should reflect your overall impression of the video unless otherwise specified.

2) On the following scale please rate your overall impression of the quality of the communication between the two people in the video you jlst viewed.

$\begin{array}{lllllllll}4 & 3 & 2 & 1 & 0 & 1 & 2 & 3 & 4\end{array}$

GOOD

NEITHER

BAD GOOD NOR BAD

3) Each of the partners probably had some feelings about the outcome of their conversation. Please indicate here how you think each partner may have felt about the final outcome:

Ted :

$$
4
$$

3

2

1

0

VERY

PLEASED

Christine:

3

2

1

0

1

2

3

NOT AT ALL

VERY

PLEASED

PLEASED 
4) In your view, was the outcome which the couple reached a good one?

$\begin{array}{lllllllll}0 & 1 & 2 & 3 & 4 & 5 & 6 & 7 & 8\end{array}$

OUTCOME WAS

OUTCOME WAS

BAD

GOOD

How come? -- (what factors influenced your opinion roncerning how good or bad the final outcome was? Please be specific.

5) If you feel that the couple's communication pattern could be improved, in what ways would you suggest that one or the other or both of the partners might change? Please be specific.

6) If this couple's relationship continues as it is presently, where would you predict that the relationship will be in six months? In other words, do you think it will be the same; do you think they will break up; do you think it will work out well; or will the relationship be worse? Please explain WHY you make the prediction you do. 
7) In your own experience, how typical of most couples' discussions was the interaction you just viewed? In other words do you think it was representative of most couples discussions in general?

$\begin{array}{lllllllll}0 & 1 & 2 & 3 & 4 & 5 & 6 & 7 & 8\end{array}$

VERY

NOT

SURE

8) If you were to place yourself in the situation of the video, you feel that you would react as the participants did, or differently? If you answer "differently", please explain how the scene would have differed.

9) If you recognized that the problems you identified above were happening during a situation you wera involved in. would you be able/willing to implement the changes you suggested above? Please explain your answer. 
a) How would you rate the success of this portion of the couple's interaction? In other words were they able to express themselves effectively and discuss the problem?

$\begin{array}{lllllllll}4 & 3 & 2 & 1 & 0 & 1 & 2 & 3 & 4\end{array}$

UNSUCCESSFUL

NEITHER

SUCCESSFUL

b) What was it about this interaction that made you feel it was relatively successful or not?

c) Now, consider Ted and Christine's individual contributions to the interaction. Did one individual contribute more to ar:y unsuccessful communication than the other?

$\begin{array}{lllllllll}4 & 3 & 2 & 1 & 0 & 1 & 2 & 3 & 4\end{array}$

Ted

contributed

more

\section{It was} eçual
Christine contributed more 
a) Did the members of the couple validate each other's opinions?

In other words, did they accept the other's points as valid even if they disagreed with them? (MA)

TED SHOWED:

$\begin{array}{lllllllll}0 & 1 & 2 & 3 & 4 & 5 & 6 & 7 & 8\end{array}$

No

Acceptance

$\begin{array}{llllllllll}\text { CHRISTINE SHOWED: } & 0 & 1 & 2 & 3 & 4 & 5 & 6 & 7 & 8\end{array}$ No

Acceptance
Complete Acceptance

Complete Acceptance

Please give an example from the video which illustrates your ratings for each partner.

b) Did the couple convey to you the feeling that they understood each other? (MA)

$\begin{array}{llllllllll}\text { TED SHOWED: } & 0 & 1 & 2 & 3 & 4 & 5 & 6 & 7 & 8\end{array}$

No

Understanding

Complete Understanding

$\begin{array}{llllllllll}\text { CHRISTINE SHOWED: } & 0 & 1 & 2 & 3 & 4 & 5 & 6 & 7 & 8\end{array}$ No
Understanding Complete Understanding

Please give an example from the video which illustrates your ratings for each partner. 
c) Did they criticize each other? (MA)

$\begin{array}{llllllllll}\text { TED SHOWED: } & 0 & 1 & 2 & 3 & 4 & 5 & 6 & 7 & 8\end{array}$
No
Criticism
A lot of Criticism

$\begin{array}{llllllllll}\text { CHRISTINE SHOWED: } & 0 & 1 & 2 & 3 & 4 & 5 & 6 & 7 & 8\end{array}$
No
Criticism
A lot of
Criticism

Please give an example from the video which illustrates your ratings for each partner.

d) Did they obviously disagree with each other? (MA)

$\begin{array}{llllllllll}\text { TED SHOWED: } & 0 & 1 & 2 & 3 & 4 & 5 & 6 & 7 & 8\end{array}$

No Obvious

Obvious

Disagreement

Disagreement

$\begin{array}{llllllllllll}\text { CHRISTINE SHOWED: } & 0 & 1 & 2 & 3 & 4 & 5 & 6 & 7 & 8\end{array}$

No Obvious

Obvious Disagreement Disagreement

Please give an. example from the video which illustrates your ratings for each partner. 
e) Did they react in an clearly negative manner or a clearly positive manner to what was being said by the other? (Mn)

TED SHOWED:

$$
\begin{array}{lllllllll}
-4 & -3 & -2 & -1 & 0 & 1 & 2 & 3 & 4
\end{array}
$$

Negative

Positive

Reaction

Reaction

CHRISTINE SHOWED: $\begin{array}{llllllllll}-4 & -3 & -2 & -1 & 0 & 1 & 2 & 3 & 4\end{array}$

Negative

Positive

Reaction

Reaction

Please give an example from the video which illustrates yc a ratings for each partner.

f) Was compromise used by this couple during the interaction? In other words were they able to reach an agreement which was acceptable to both parties? (COOP)

$\begin{array}{llllllllll}\text { TED : } & 0 & 1 & 2 & 3 & 4 & 5 & 6 & 7 & 8\end{array}$

Compromise $\quad \stackrel{N}{N} \stackrel{0}{\text { Compromise }}$

$\begin{array}{llllllllll}\text { CHRISTINE : } & 0 & 1 & 2 & 3 & 4 & 5 & 6 & 7 & 8\end{array}$

Compromise No

Compromise

Please give an example from the video which illustrates your ratings for each partner. 
g) Did this couple treat the situation as "Win or Lose"? In other words did they seem to expect that one person would win and the other would lose in the end? (COOP)

TED:

$\begin{array}{lllllllll}0 & 1 & 2 & 3 & 4 & 5 & 6 & 7 & 8\end{array}$

Situation WAS

Win or Lose

$\begin{array}{llllllllll}\text { CHRISTINE: } & 0 & 1 & 2 & 3 & 4 & 5 & 6 & 7 & 8\end{array}$

Situation WAS

Win or Lose
Situation was NOT win or Lose

Situation was NOT win or Lose

Please give an example from the video which 'llustrates your ratings for each partner.

h) Was the communication of each partner clear or was it vague? (OPEN)

TED :

$0 \quad 12$

34

$\begin{array}{llll}5 & 6 & 7 & 8\end{array}$

Vague

Clear

$\begin{array}{llllllllll}\text { CHRISTINE: } & 0 & 1 & 2 & 3 & 4 & 5 & 6 & 7 & 8\end{array}$

Vague

Clear

Please give an example from the video which illustrates your ratings for each partner. 
i) Was the communication of each partner direct or was it indirect?

In other words, did ecch gartner seem to say what they mean, or did there seem to be "hidden" meanings in their conumunication? (OPEN)

TED :

01

Direct

Indirect

$\begin{array}{llllllllll}\text { CHRISTINE: } & 0 & 1 & 2 & 3 & 4 & 5 & 6 & 7 & 8\end{array}$

Direct

Indirect

Please give an example from the video which illustrates your ratings for each partner.

j) Was each partner open to communication from the other? In other words, did they iisten to what each other said and were they receptive to their partner's ideas (OPEN), or did they ignore each other and dismiss each other's ideas (CLOSED)? (OPEN)

TED:

$\begin{array}{lllllllll}0 & 1 & 2 & 3 & 4 & 5 & 6 & 7 & 8\end{array}$

Open

Closed

$\begin{array}{llllllllll}\text { CHRISTINE: } & 0 & 1 & 2 & 3 & 4 & 5 & 6 & 7 & 8\end{array}$
Open
Closed

Please give an example from the video which illustrates your ratings for each partner. 
k) Was each partner likely to accuse the other? (COOP)

$\begin{array}{llllllllll}\text { TED : } & 0 & 1 & 2 & 3 & 4 & 5 & 6 & 7 & 8\end{array}$

Accuse

Accused

Did not

$\begin{array}{llllllllll}\text { CHRISTINE : } & 0 & 1 & 2 & 3 & 4 & 5 & 6 & 7 & 8\end{array}$

Accuse

Accused

Did not

Please give an example from the video which illustrates your ratings for each partner.

1) Did each partner appear to be willing to work together to find a solution? (COOP)

$\begin{array}{llllllllll}\text { TED: } & 0 & 1 & 2 & 3 & 4 & 5 & 6 & 7 & 8\end{array}$

Willing to

Work Together

Not willing to Work Together

$\begin{array}{llllllllll}\text { CHRISTINE : } & 0 & 1 & 2 & 3 & 4 & 5 & 6 & 7 & 8\end{array}$

Willing to

Not willing to

Work Together

Work Together

Please give an example from the video which illustrates your ratings for sach partner. 
m) Was each partner likely to "blame" the other for their predicament ir for any difficulty they had in solving the problem? (COOP)

TED:$$
3
$$

45

56

$\begin{array}{lll}6 & 7 & 8\end{array}$

\section{Blamed}

Christine

Did not blame Christine

$\begin{array}{llllllllll}\text { CHRISTINE : } & 0 & 1 & 2 & 3 & 4 & 5 & 6 & 7 & 8\end{array}$

\section{Blamed}

Ted

Did not blame Ted.

Please give an example from the video which illustrates your ratings for each partner.

n) Did each partner appear to be "super-reasonable"? In other words, make themselves look agreeable to anything whether they really agreed or not? (ExCLuDED)

TED:

$$
\begin{array}{lllllllll}
0 & 1 & 2 & 3 & 4 & 5 & 6 & 7 & 8
\end{array}
$$

"Super-

NOT "Super-

Reasonable" Reasonable"

$\begin{array}{llllllllll}\text { CHRISTINE: } & 0 & 1 & 2 & 3 & 4 & 5 & 6 & 7 & 8\end{array}$

"Super-

NOT "SuperReasonable" Reasonable"

Please give an example from the video which illustrates "ivur ratings for each partner. 
o) Was each partner able to express their feelings to the other partner? (OREN)

TED:

$\begin{array}{lllllllll}0 & 1 & 2 & 3 & 4 & 5 & 6 & 7 & 8\end{array}$

Expressed

his feelings
Did NOT express his feelings

$\begin{array}{llllllllll}\text { CHRISTINE : } & 0 & 1 & 2 & 3 & 4 & 5 & 6 & 7 & 8\end{array}$

Expressed her feelings

Did NOT express her feelings

Please give an example from the video which illustrates your ratings for each partner.

P) Was each partner able to express to the other partner their preferences for what they wanted to do at Christmas?

(EXCLUDED)

$\begin{array}{llllllllll}\text { TED: } & 0 & 1 & 2 & 3 & 4 & 5 & 6 & 7 & 8\end{array}$

Expressed

his preferences
Did NOT express his preferences

$\begin{array}{llllllllll}\text { CHRISTINE : } & 0 & 1 & 2 & 3 & 4 & 5 & 6 & 7 & 8\end{array}$

Expressed

her preferences

Did NOT express her preferences

Please give an example from the video which illustrates your ratings for each partner. 
q) Did each member use the discussion of the problem to make a generalized attack on the other? (Focus)

TED:

$\begin{array}{lllllllll}0 & 1 & 2 & 3 & 4 & 5 & 6 & 7 & 8\end{array}$

Generalized

At.tack

NO Generaiized Attack

$\begin{array}{llllllllll}\text { CHRISTINE : } & 0 & 1 & 2 & 3 & 4 & 5 & 6 & 7 & 8\end{array}$

Generalized

Attack

NO Generalized Attack

Please give an example from the video which illustrates your ratings for each partner.

r) Did each member appear to focus on the problem at hand? (FOCUS)

TED:

$\begin{array}{lllllllll}0 & 1 & 2 & 3 & 4 & 5 & 6 & 7 & 8\end{array}$

Focussed

on the problem
Did NOT focuss on the problem

$\begin{array}{llllllllll}\text { CHRISTINE : } & 0 & 1 & 2 & 3 & 4 & 5 & 6 & 7 & 8\end{array}$

Focussed

on the problem
Did NOT focuss on the problem

Please give an example from the video which illustrates your ratings for each partner. 
s) How sensitive did each member seem to be to the other's feelings? (OPEN)

$\begin{array}{llllllllll}\text { TED : } & 0 & 1 & 2 & 3 & 4 & 5 & 6 & 7 & 8\end{array}$

Insensitive

Sensitive

$\begin{array}{llllllllll}\text { CHRISTINE: } & 0 & 1 & 2 & 3 & 4 & 5 & 6 & 7 & 8\end{array}$

Insensitive

Sensitive

Please give an example from the video which illustrates your ratings for each partner.

t) Non-verbal behaviour (i.e., tone of voice, body language, general attitude to each other) can be more on the negative side or more on the positive side. Which did each individual show more of in this interaction? (Norr)

TED:

$\begin{array}{lllllllll}-4 & -3 & -2 & -1 & 0 & 1 & 2 & 3 & 4\end{array}$

Negative

Both

Equally

Positive

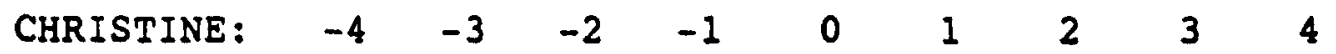

Negative

Both

Equally

Positive

Please give an example from the video which illustrates your ratings for each partner. 
u) Was their non-verbal communication in line with their verbal communication? In other words, did what they said "go together" with their tone of voice and/or body language, or did they sometimes 'say' one thing, but clearly feel'something else given how they said it or showed it? (EXCLUDED)

TED:

$\begin{array}{lllllllll}0 & 1 & 2 & 3 & 4 & 5 & 6 & 7 & 8\end{array}$

\section{Did not go \\ together}

$\begin{array}{llllllllll}\text { CHRISTINE: } & 0 & 1 & 2 & 3 & 4 & 5 & 6 & 7 & 8\end{array}$

$$
\begin{gathered}
\text { Did not go } \\
\text { together }
\end{gathered}
$$

Did go together

Please give an example from the video which illustrates your ratings for each partner.

v) When one partner was listening to the other was their non-verbal behaviour more NEGATIVE, (i.e., they looked away from the other; they looked as though they were not listening), or more POSITIVE (i.e., they looked at the other; they seemed to be listening?). (HONV)

TED:

$$
\begin{array}{lllllll}
-4 & -3 & -2 & -1 & 0 & 1 & 2
\end{array}
$$

34

$$
\text { Negative }
$$

Positive

CHRISTINE: $\quad \begin{array}{lllllllll}-4 & -3 & -2 & -1 & 0 & 1 & 2 & 3 & 4\end{array}$

Negative

Positive

Please give an example from the video which illustrates your ratings for each partner. 
Please respond to the following questions about yourself.

nore: By "family" we mean the people you consider your family. This might include "biological", "adopted", "foster", or "step" families.

1) How many people are in your family?

Parents

Step-parents

Sisters

Brothers

Others (please explain)

2) What is your placement among the children in the family?

Oldest
"Middle"
Youngest -
Only Child

3) Do you presently live with your family?

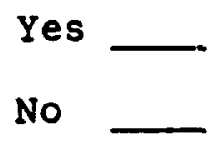

If No, how long have you been on your own? 
4) Are you currently in a romantic relationship?

$\begin{array}{lll}\text { Yes } & \text { (PLEASE CONTINUE WITH PART A) } \\ & \text { No } & \text { (PLEASE SKIP TO PART B) }\end{array}$

PART A:

a) Would you consider this relationship "intense"? (i.e., you have a serious emotional commitment to each other.)

$\begin{array}{lllllllll}0 & 1 & 2 & 3 & 4 & 5 & 6 & 7 & 8\end{array}$

NOT AT ALL

b) How long have you been in this relationship?

c) Is your partner in town with you?

$$
\text { Yes }
$$

d) How would you rate your relationship?

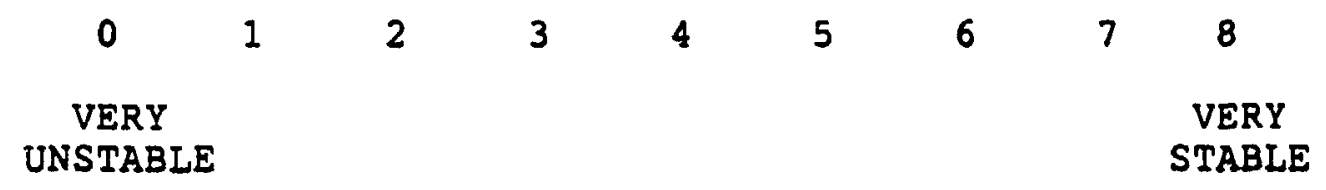

(please skip to question 5) 
PART B:

a) Are you looking to enter into a romantic relationship with anyone? (Speaking in general terms. You need not have someone specific in mind.)

Yes

No

How intense would you want the relationship to be? (by "intense" we mean a serious emotional commitment to each other.)

$\begin{array}{llllllllll}\begin{array}{c}\text { NOT AT ALL } \\ \text { INTENSE }\end{array} & 0 & 1 & 2 & 3 & 4 & 5 & 6 & 7 & 8 \begin{array}{r}\text { VERY } \\ \text { INTENSE }\end{array}\end{array}$

5) Have you ever had an intense relationship in the past? Yes _ How many?

No

6) Do you have what you would consider "close friends". In other words, someone you could talk to about anything, with whom you are always close, and if you are apart, you feel as if nothing has changed when you reunite.

PRESENTLY

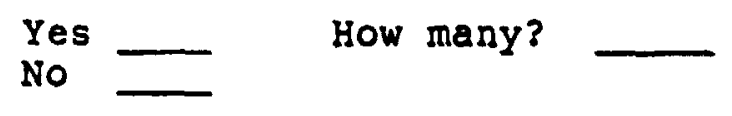

IN THE PAST?

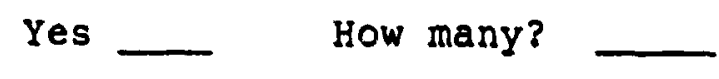

No 
7) Have you been involved in groups or programs with the following emphases (please check those that apply)?

\section{(I) How long? Started}

Addiction Counselling

Adult Children of Alcoholics

ALATEEN

Drug Awareness Programs

Family Counselling

Life Skills Training

Marital Counseling

Pastoral Counselling

(e.g., clergy or priest)

Personal Counselling

Self Awareness/Self help

Seminars

Therapy or Psychotherapy

other

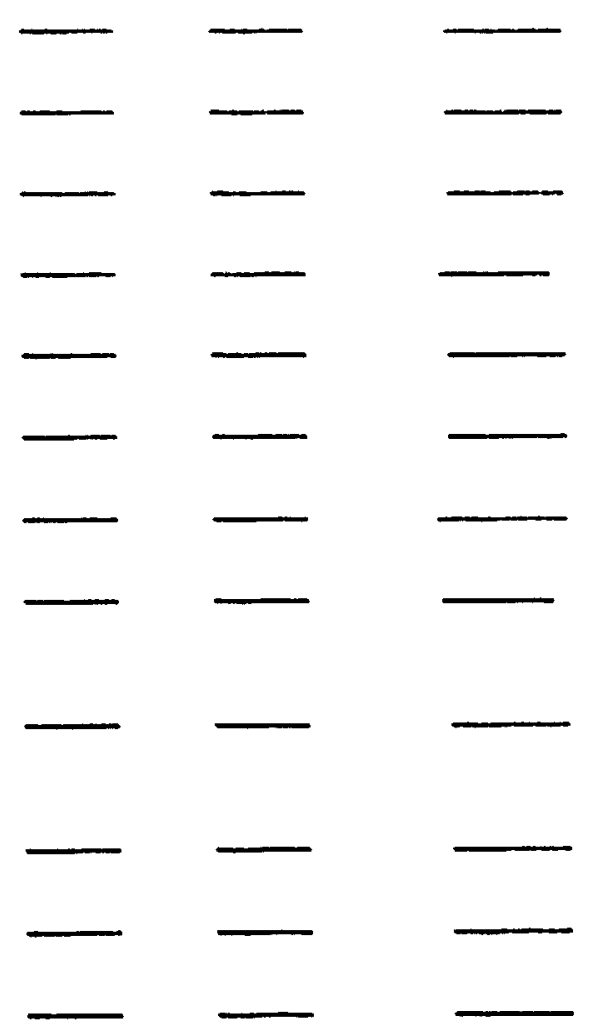

COMMENTS : 


\section{APPENDIX E}


Scoring Criteria for Perception of Communication Study

ITEMS RECALLED

Both are reading

- Christine hesitates/something appears to be on her mind

- Chris kirings up subject

- Ted hesitates/annoyed at being interrupted

- Chrisine insists they talk

- Discuss what Christmas means to each family

- Discuss who will be at each family's

- Suggestion to spend the holidays apart

- Realize both want to go to their respective families/decide to compromise

- Discuss whether they ve compromised in the past. (Chris a lways gets her way)

Discuss apartment

- Discuss car

- Christine denies she always gets her way

- Realize this is not the issue and return to discussion of $X$-mas

- Suggest they go to Ted's as fewer children there.

- Offer compromise of $X$-mas at his place and New years at hers. Christine accepts compromise

- Discuss telling parents and making travel arrangements

- Chris tell Ted to read his article

- Joke about not having to make plans again until Easter

1) FREE RECALL (CONT'D)

a) Was there embellishment? (i.e. did $s$ add or misconstrue events?)

$\begin{array}{cccc}0 & 1 & 2 & 3 \\ \text { never } & \text { once } & \text { twice } & \text { three or more times }\end{array}$

b) Does $\mathrm{S}$ describe/mention emotions (e.g., the characters were angry, pleased sarcastic, happy, annoyed, agreeable)?

$$
\begin{array}{cccc}
0 & 1 & 2 & 3 \\
\text { never } & & 4 \\
\text { often/detailed }
\end{array}
$$


c) Did the $s$ judge or take sides?- (favouring one cahracter over the other)

$$
\begin{array}{cccc}
\begin{array}{c}
0 \\
\text { never }
\end{array} & 2 & 2 & { }^{3} \\
\text { WHOSE } & & \text { took one side completely }
\end{array}
$$

d) Was the S's overall tone/attitude toward the interaction positive, negative, or neutral? (lowk for tone toward interaction (reading affect into the video))

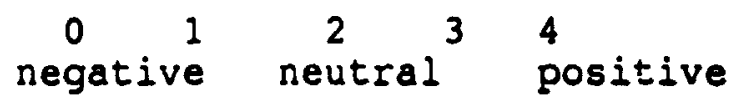

4) OUTCOME GOOD/BAD

a) Is an example given? Yes/no

b) how many factors are listed?

c) Are the factors correct? (one point each) e.g. if GOOD

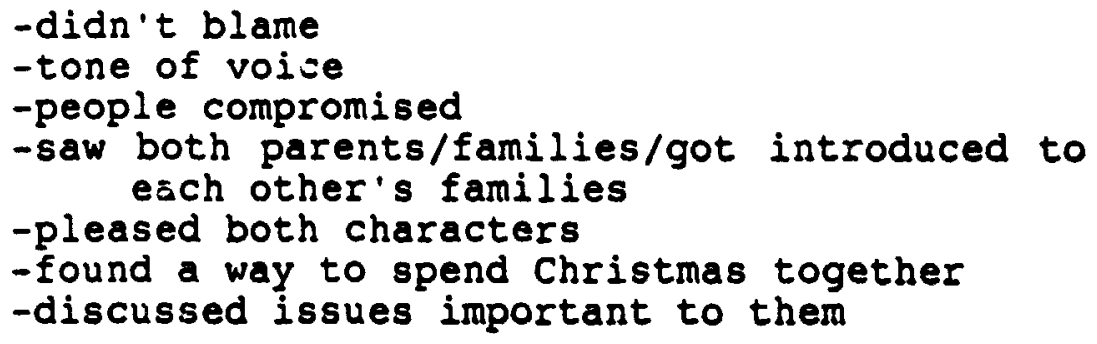

d) How detailed was the response?

$\begin{array}{llllll}\begin{array}{l}\text { Vague } \\ \text { unclear }\end{array} & 2 & 3 & 4 & 5 & \begin{array}{l}\text { specific } \\ \text { clear } \\ \text { generalized }\end{array} \\ & & & & & \text { detailed }\end{array}$


5) SUGGEST IMPROVEMENTS

a) Did the $S$ suggest improvements? $Y / N$

b) Were they correct?

- jumped to conclusions (1)

- focus on the issue more (2)

-listen to each other more (2)

-react positively to what the other person says (2)

- consider each other's feelings (2)

- better communication (1)

-bad communication (0)

-went off topic - car,apt. (2)

-Find decision both are happy with

-Express own feelings clearly (2)

-shouldn't assume what people think (2)

-Shouldn't balme each other (2)

c) Were the suggestions one-sided (only one character should improve)?

$\begin{array}{cccc}1 & 2 & 3 & 4 \\ \text { neutral } & & & \text { Completely one sided } \\ \text { WHOSE }\end{array}$

d) How detailed was the response?

$\begin{array}{llllll}\text { Vague } & 1 & 2 & 3 & 4 & 5\end{array}$ specific

unclear

generalized

clear

detailed

6) PREDICT WHERE RELATIONSHIP WILL BE

a) Does the $S$ make a prediction? $Y / N$

b) What is their prediction?

$\begin{array}{cclll}0 & 1 & 2 & 3 & 4 \\ \text { Don't know } & \text { Breakup will worsen } & \text { same } & w & \end{array}$ better/workout

d) How detailed was the response?

$\begin{array}{lllllll}\text { Vague } & 1 & 2 & 3 & 4 & 5 & \begin{array}{l}\text { specific } \\ \text { clear } \\ \text { unclear }\end{array} \\ \text { generalized } & & & & & \begin{array}{l}\text { detailed } \\ \text { detale }\end{array}\end{array}$


8) WHAT WOUID YOU DO DIFFERENTLY?

a) Is this answered? $Y / N$

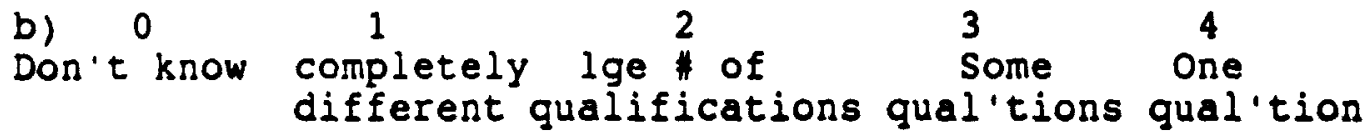

5

Exactly

the

same

C) Was the difference a positive or a negative one?

e.g. POSITIVE (one point each)

- more compromise

-listen to each other more

-not get distracted by other issues (the past)

-pay attention to one another's needs

-no blaming

-speaking calmly

-express self/needs better

e.g. NEGATIVE (-1 point each)

-could not compromise

-wouldn't discuss it

-would just do whatever my partner wanted

-would want my way

e.g NO DIFFERENCE

-is reason positive? (1)

- negative? $(-1)$

-did they focus on outcome? (0)

-no reasons $(0)$

process? (1)

9) COULD YOU IMPLEMENT CHANGES?

a) Did $S$ answer the question? $Y / N$

b) What did they answer? $y / n / d o n ' t$ know 
B) WHAT MADE THE INTERACTION SUCCESFUL OR NOT?

a) Did they focus on the positive or the negative?

$\begin{array}{ccccc}1 & 2 & 3 & 4 & 5 \\ \text { negative } & & \text { neutral } & & \text { positive }\end{array}$

b) Was the example one-sided?

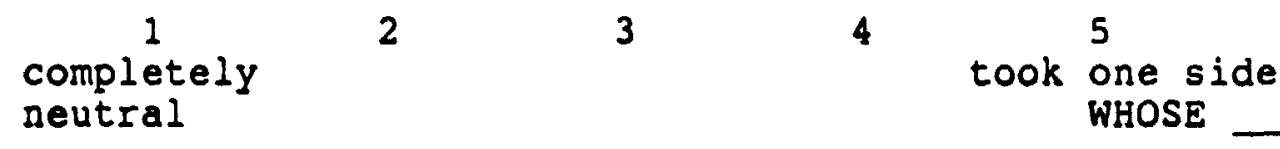

c) How many reasons did they give?

d) Were they correct?(SEE \# 4 and \# 8 , one point each)

e) How detailed was the response?

$\begin{array}{llllll}\begin{array}{l}\text { Vague } \\ \text { unclear }\end{array} & 2 & 3 & 4 & 5 & \begin{array}{l}\text { specific } \\ \text { clear } \\ \text { generalized }\end{array} \\ & & & \text { detailed }\end{array}$

f) Did the focus on the outcome or the process?

$\begin{array}{ccccc}1 & 2 & 3 & 4 & 5 \\ \text { outcome } & & \text { both } & & \text { process }\end{array}$




\section{References}

Barnes, G.M., Farrel, M.P., \& Cairns, A. (1986). Parental socialization factors and adolescent drinking behaviours. Journal of Marriage and the Family, 48(1), 27-36.

Bateson, G., Jackson, D.D., Haley, J., \& Weakland, J. (1956). Toward a theory of schizophrenia. Behavioral science, 1 , 251-264.

Bell, R.Q., \& harper, L.V. (1977). Child Effects on Adults. Hillsdale, N.J.: Lawrence Erlbaum Assoc. (chaps. $8 \& 9$ ).

Belsky, J. (1981). Early human experience: A family perspective. Developmental Psycholooy, 17, 3-23.

Clarke-Stewart, A., Friedman, S., \& Koch, J. (1985). Child Development. A Topical Approach. New York: John Wiley and sons.

Epstein, N.B., Baldwin, L.M., \& Bishop, D.S. (1983). The McMaster Family Assessment Device. Journal of Marriage and Family Therapy, 9 , 171-180.

Filsinger, E.E., \& Lamke, L.K. (1983). The lineage transmission of interpersonal competence. The Journal of Marriage and the Family, 45(1), 75-80.

Fliess, J. (1981). Chapter 13: The measurement of incerrater aggreement. Statistical Methods for Rates and Proportions. Second Edition. New York: John Wiley Pub., 212-237.

Forman, B.D. \& Hagan, B.J., (1001). Measures for evaluating total family functioning. Family Therapy, 11(1), 1-36.

Gecas, V., \& Schwalbe, M.L. (1986). Parental behaviour and adolescent self-esteem. Journal of Marriage and and the Family, 48(1), 37-46.

Gottman, J., Notarius, C., Gonso, J., \& Markman, H.J. (1976). A Couple's Guide to Communication. Champaign, Ill.: Research Press.

Gottman, J.M. (1979). Marital Interaction: Experimental Investigations. New York: Academic Press.

Hoffman, L., Paris, S., Hall, E., \& Schell, R., (1988). Developmental Psychnlogy Today, 5th edition. New York: Random House. 
Hooley, J.M., \& Hahlweg, K. (1989). Marital satisfaction \& marital communication in German and English couples. Behavioral Assessment, 11, 119-133.

Hyde, J.S. and Rosengerg, B.G. (198C). Half the Human Experience. Secolid Edition. Toronto: D.C. Heath and Company.

Keppel, G. (1982). Design and Analysis: A Researchers Handbook. New Jersey: Prentice-Hall Inc.

Lidz, I., Conelison., A.R., Fleck, S., \& Terry, D. (1957). The intrafamilial environment of schizophrenic patients: I Marital Schism \& Marital Skew. The American Journal of Psychiatry, 114, 241-248.

Lobdell, J., \& Perlman, D. (1986). The intergenerational transmission of Loneliness: A study of college females and their families. Journal of Marriage and the Family, $48(3)$, 589-595.

Macoby, E.E., \& Martin, J.A. (1983). Socialization in the context of the family. In P.H. Mussen (Ed.), Handbook of Child Psychology, 4th edition, vol 4, 1-101. New York: Wiley (Chap. 9).

Markman, H.J. (1991). Prediction of marital distress, A five year follow-up. Journal of Consulting and Clinical Psychology, 49, 760-762.

Masters W.H., J Johnson, V.E. (1979). Homosexuality in Perspective. Boston: Little, Brown.

Mayo, C. and Henley, N.M. (Eds.) (1981). Gender and Nonverbal Behavior. New York: Springer-Veriag.

Miller, R.B., Glass, J. (1989). Parent attitude similarity across the life course. Journal of Marriage and the Family, 51(4), 991-997.

Murphy, D.C. \& Mendelson, L.A. (1973). Communication and adjustment in marriage: Investigating the relationships. Family Process, 34, 621-626.

Nadler, L.B., Nadler, M.K., Todd-Mancillas, W.R. (1987). Advances in Gender and Communication Research. New York: University Press of America Inc.

Navran, I. (1967). Communication and adjustment in Marriage. Family Process, $6,173-184$. 
Olson, D.H. (1970). Marital and family therapy: Integrative review and critique. Journal of Marriage and the Family, $\underline{32}, 501-538$.

Santrock, J.W., Yussen, S.R. (1989). Child Development: An Introduction, 4 th edition. Iowa: W.C. Brown Publishers.

Satir, V. (1972). Peoplemaking. California: Science and Behavior Books, Inc.

Satir, V. (1983). Step by Step. California: Science and Behavior Books, Inc.

Seiberg, E. (1985). Family Communication: An Integrated Systems Approach. New York: Gardner Press, Inc.

Stewart, L.P. and Ting-Toomey, S. (eds) (1987). Communication, Gender, and Sex Roles in Diverse Interaction Contexts. New Jersey: Ablex Publishing Corp.

Tabachnik, B.G. and Fldell, L.S. (1983). Using Multivariate statistics. New York: Harper and Row.

Wynne, L.C., Ryckoff, I.M., Day, J., \& Hirsch, S.I. (1958). Pseudo-mutuality in the family relations of schizophrenics. Psychiatry, 21, 205-220. 

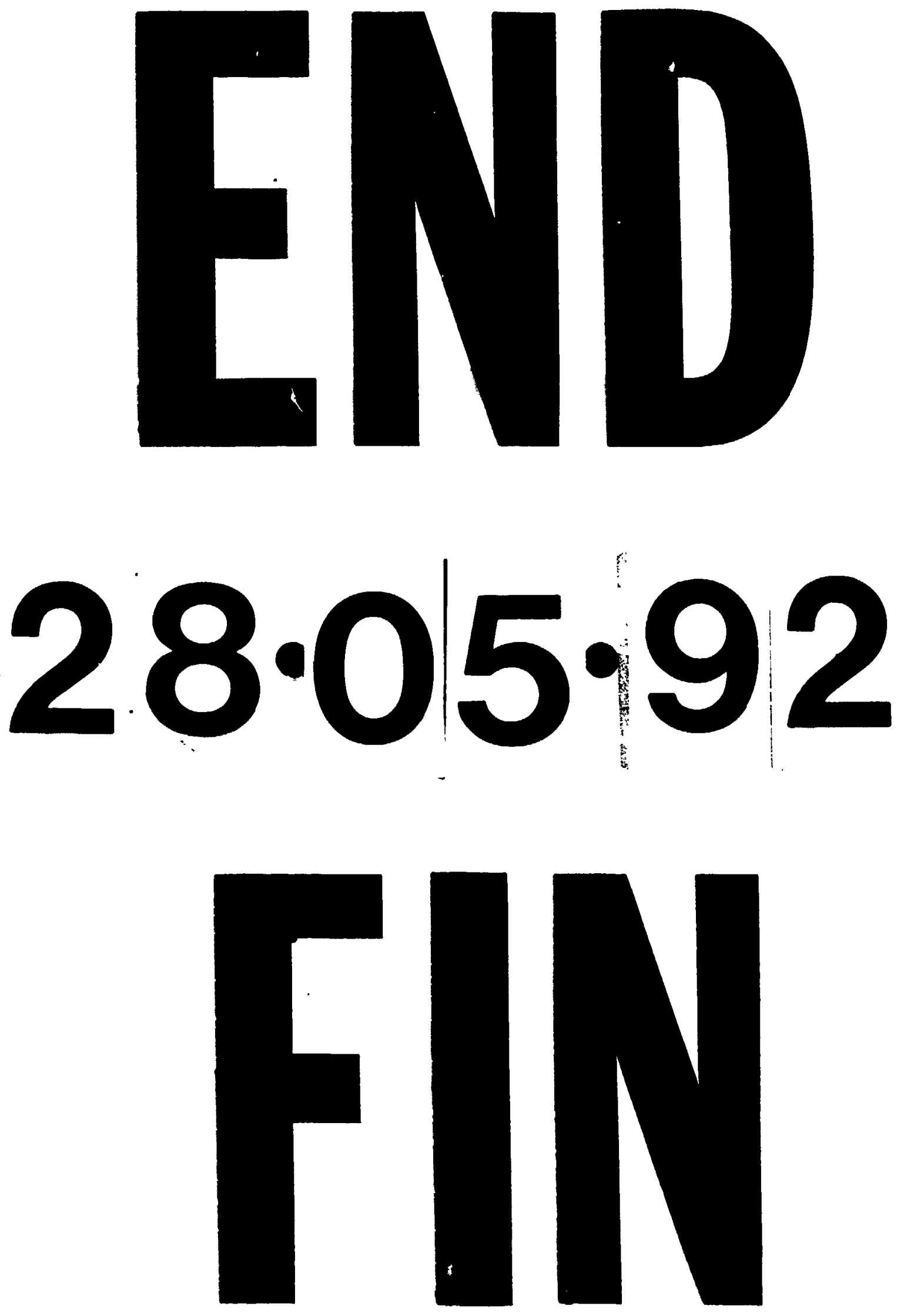